\title{
INDUSTRIAL GROUPINGS AND STRATEGIC FDI: THEORY AND EVIDENCE
}

\author{
Bruce A. Blonigen \\ Christopher J. Ellis \\ Dietrich Fausten \\ Working Paper 8046 \\ http://www.nber.org/papers/w8046

\section{NATIONAL BUREAU OF ECONOMIC RESEARCH 1050 Massachusetts Avenue \\ Cambridge, MA 02138} \\ December 2000
}

We thank Ron Davies for several useful comments. The views expressed in this paper are those of the authors and not necessarily those of the National Bureau of Economic Research.

(C) 2000 by Bruce A. Blonigen, Christopher J. Ellis, and Dietrich Fausten. All rights reserved. Short sections of text, not to exceed two paragraphs, may be quoted without explicit permission provided that full credit, including (C) notice, is given to the source. 
Industrial Groupings and Strategic FDI: Theory and Evidence

Bruce A. Blonigen, Christopher J. Ellis, and Dietrich Fausten

NBER Working Paper No. 8046

December 2000

JEL No. F10, F21, F23

\section{ABSTRACT}

We show that industrial ownership structures, such as keiretsu groupings in Japan, may significantly impact firms' incentives to engage in FDI. While the previous literature has mainly focused on the cost of capital advantages enjoyed by keiretsu firms, this paper examines two relatively unexplored channels by which ownership structure matters for FDI incentives. The first channel involves the direct incentives generated via standard product and factor market interactions whereby keiretsu firms with cross-ownership consider more directly the congestion effects of further FDI into a market. The second channel involves the indirect incentives generated by sharing of information across keiretsu firms which reduces entry costs for subsequent FDI. Using data on Japanese FDI activity by both keiretsu and non-keiretsu manufacturing firms, we find evidence to support the importance of the second channel (information-sharing incentives) as an explanation for firm-level FDI patterns, but not for the first channel.

Bruce A. Blonigen

Department of Economics

1285 University of Oregon

Eugene. OR 97403-1285

and NBER

bruceb@oregon.uoregon.edu

Dietrich Fausten

Department of Economics

Monash University

Clayton 3168 Victoria

Australia

dietrich.fausten@buseco.monash.edu.au
Christopher J. Ellis

Department of Economics

1285 University of Oregon

Eugene, OR 97403-1285

cjellis@oregon.uoregon.edu 


\section{Introduction.}

It has frequently been suggested that firms in the large industrial groupings of Japan and Korea, known respectively as keiretsu and chaebol, may behave differently from their US or European counterparts. Members of these industrial groupings hold ownership shares in each other, obtain repeated financing from associated member banks, and participate on joint committees. ${ }^{1} \quad$ For each of these reasons it has been argued that the structure of keiretsu and chaebol lead their member firms to behave (semi)cooperatively. Consequently, they may be expected to internalize externalities and find ways to mitigate the problems implied by information asymmetries. ${ }^{2}$ It has been further noted that cross-shareholding structures can also weaken a firm's bargaining position and dilute its market incentives, Flath [8] Flath [9].

The purpose of this paper is to explore the relationships between industrial ownership structure and the incentives for firms to carry out foreign direct investment (FDI). It has been alleged that (semi)cooperative industrial ownership structures, such as the Japanese keiretsu system, yield their members advantages in exploiting opportunities for FDI. Typically these advantages are explained as arising from access to cheap funds for investment. While these stories seem quite plausible, the empirical support for them has been somewhat mixed (see Belderbos and Sleuwaegen [3], Hoshi, Kashyap, and Scharfstein [15], Fukao, Izawa, Kunimori and Nakakita [11], and McKenzie [21]). In this paper we take a different approach. Rather than concentrate on the implications of ownership structure for the financing of FDI, we instead focus, first, on the implications it has for the strategic incentives to invest that arise through the interactions between firms on input and output markets, and, second, on the incentives it provides for information generation and dissemination.

Our paper contains both theoretical and empirical sections. We first develop an illustrative theoretical model similar to that proposed in the literature on the adoption of new technology

\footnotetext{
${ }^{1}$ Bank representatives also sit on the boards of associated firms.

2 See for example Suzuki [25], Dewenter and Warther[5], Kimura and Pugel [16].
} 
by Fudenberg and Tirole [10]. FDI decisions are modelled as entry probabilities in a mixed strategy equilibrium to a game in stages. We model the factor and product market interactions by allowing the firms' payoffs to change as successive entry takes place. The information aspect of the process is captured by assuming that entry costs are a declining function of the total number of prior investments. To further capture the salient features of the FDI process we assume some information is public, and is generated as an externality to be enjoyed by all potential entrants, whereas some of the information is private, and is only transmitted between firms engaged in cooperative relationships.

Modelling FDI decisions as entry probabilities in a mixed strategy equilibrium has previously been proposed by Linn and Saggi [19] and Ellis and Fausten [6]. Our analysis, though still not fully general, considerably extends these earlier contributions. Linn and Saggi examined a single stage game between two competitive firms so as to obtain the comparative statics properties of the initial entry probability decision, and the optimal delay between initial and subsequent entry. Ellis and Fausten followed the same path as Linn and Saggi but introduced overlapping share ownership into the model to analyze the implications for FDI of different ownership structures. Our work makes two key further extensions, we introduce a third firm into the analysis and allow for asymmetric information between firms. Introducing a third firm might seem minor, yet it is significant in three ways; (1) It allows us to consider strategic interactions between a pair of (semi)cooperative firms and a competitive rival; (2) It allows the FDI entry game to be split into a sequence of stages, each of which is characterized by equilibrium entry probabilities, allowing examination of the relationships between entry probabilities over time; and, (3) It allows private information to play a significant role, as an early entrant must consider the subsequent asymmeties in information that may be gernerated by its entry.

Our extension to a three firm game in stages also allows us to bring the evidence from the available data to bare on the theory. As with previous studies, we use a firm-level database of Japanese FDI activity and match firms with their keiretsu groupings. However, as suggested by theory, we 
pursue a much different empirical specification than that explored by previous studies that have only examined whether keiretsu inclination per se increases FDI probabilities. Our theory suggests that keiretsu affiliation effects on FDI entry decisions work through the interconnectedness of firms' FDI decisions, rather than as an independent effect. Therefore, we examine whether initial entry by keiretsu firms in a destination country have different impacts on subsequent entry probabilities by firms of the same keiretsu versus those of non-keiretsu firms. Consistent with the hypothesis that private information sharing amongst keiretsu firms substantially reduces entry costs, we find that previous investment by keiretsu firms leads to significantly higher entry probabilities by other keiretsu-member firms. However, we find little evidence that cross-ownership shares affect FDI entry probabilities. Our specification outperforms a model of FDI probability that only includes keiretsu affiliation as an independent factor.

\section{The Theoretical Model.}

When firms contemplate locating production facilities outside of their home countries they face a difficult trade-off. If they invest early they may gain advantages on both product and input markets. However, in moving early they also face a host of potential problems, for example it takes time to learn how to operate efficiently in a foreign labor market and under a foreign legal system. Thus the initial fixed costs of investment may be high. If, on the other hand, they delay entry, they will forgo some of the product and factor market advantages enjoyed by early entrants, but may gain valuable information from observing their predecessors. This information will reduce the fixed costs of initial entry. The theoretical model we now develop captures this basic tension.

\subsection{Basic Structure.}

We assume that there are three firms that may produce output either in their domestic economy(ies) or abroad via FDI. The three firms may be either fully independent, as in the case of most US firms or, alternatively, they may be partially cooperative, as for example when linked via overlapping shareholdings, such as in the cases of Japanese keiretsu and Korean chaebol members. 
We assume that initially all three firms are engaged in domestic production, and that at each subsequent point in time each must choose either to continue in this production mode, $m=D$, or make an irreversible switch to foreign production, $m=F$. At any time $t$ the flow profit enjoyed by firm $n$ from choosing a production mode given the modes of production chosen by the other two firms is written

$$
\begin{gathered}
\Pi^{n}(t)=\Pi^{n}\left[m^{n}(t) \mid m^{i}(t), m^{j}(t)\right] \\
n=1,2,3, i=1,2,3, j=1,2,3, n \neq i \neq j .
\end{gathered}
$$

Often we shall adopt shorthand notation of the form $\Pi^{1}\left[D^{1}(t) \mid D^{2}(t), F^{3}(t)\right] \equiv \Pi_{D D F}^{1}{ }^{3}$.

To capture the idea that there are advantages to early investment we assume that profits will vary across the different combinations of domestic production and FDI in the following manner

$$
\Pi_{F D D}^{n}>\Pi_{F F D}^{n}=\Pi_{F D F}^{n}>\Pi_{F F F}^{n}>\Pi_{D D D}^{n}>\Pi_{D F D}^{n}=\Pi_{D D F}^{n} \geq \Pi_{D F F}^{n} \forall n .
$$

Thus in the absence of any relocation costs each firm would independently prefer to undertake FDI. These inequalities may be generated in several ways. They may reflect either Cournot or Bertrand competition in the product market (see Lin and Saggi [19]), where early entrants face lower marginal costs and hence a market advantage, or, alternatively, they may purely reflect labor costs where FDI allows the firms to exploit cheap labor in the host country, but where repeated entry raises labor demand and hence wages in the appropriate labor pool ${ }^{4}$.

To characterize the different potential forms of industrial ownership structure we introduce the parameter $\beta_{n}^{i}$ which represents the claim of firm $i$ on the profits of firm $n .^{5}$ So if we denote the total flow profits of firm $n$ as $P^{n}$ we may write the possibilities as

\footnotetext{
${ }^{3}$ In this notation we shall always adopt the convention that firms will be listed in the sequence $1,2,3,1,2$ etc i.e.in ascending order except that 1 will follow 3 .

${ }^{4}$ For example Feenstra and Hanson [7] find that for regions of Mexico in which FDI is concentrated more than $50 \%$ of the increase in the total wages of skilled workers can be attributed to the effects of foreign capital inflows.

${ }^{5}$ In the Japanese keiretsu system there are other mechanisms by which cooperation may be induced between members. Then role of associated commercial banks in providing repeated funding to members, and the placement of bank officials in senior positions in the members hierarchies seem particulaly important. $\beta$ may therefore be interpreted more widely as a measure of cooperation rather than simply cross shareholdings.
} 


$$
\begin{gathered}
P_{m^{n}, m^{i}, m^{j}}^{n}=\left(1-\sum_{i \neq n} \beta_{n}^{i}\right) \Pi_{m^{n}, m^{i}, m^{j}}^{n}+\sum_{i \neq n} \beta_{i}^{n} \Pi_{m^{i}, m^{j}, m^{n}}^{i} \\
n=1,2,3, i=1,2,3, j=1,2,3, n \neq i \neq j
\end{gathered}
$$

What distinguishes our model from its antecedents is the ability to analyze strategic FDI when there are both cooperative and non-cooperative firms in the population. We therefore concentrate on this case and assume that firms 1 and 2 are members of a symmetric keiretsu, so $\beta_{2}^{1}=\beta_{1}^{2}>0$, while firm 3 is purely competitive, so $\beta_{3}^{1}=\beta_{1}^{3}=\beta_{2}^{3}=\beta_{3}^{2}=0$. We may now utilize this structure to examine the firms' FDI decisions in an economy where some firms are linked through industrial groupings and other are not.

\subsection{The Firms' Problem.}

At some initial date $t=0$ each firm is engaged exclusively in domestic production. ${ }^{6}$ The problem each must solve is if and when to switch to FDI given that switching production from one country to another is clearly costly ${ }^{7}$. We assume that the cost a firm incurs in switching from domestic to foreign production is a decreasing function of the number of firms that have already switched. The idea here is that there is cost reducing information that may be obtained by learning from the entry experiences of preceding firms. However, we also assume that while some of this information is publicly available, some is private and will be transferred only between firms in the same industrial grouping. ${ }^{8}$ We define the entry date of the first firm as $t=t^{*}$, the second as $t=t^{* *}$, and the third as $t=t^{* * *}$, naturally $t^{*} \leq t^{* *} \leq t^{* * *}$. We thus express the entry costs as ${ }^{9}$

\footnotetext{
${ }^{6}$ We might think of this as the time at which FDI became a potentially lower cost mode of production. Either because of the relaxation of legal restriction by the host country, an improvement in the host countries labour force, or an increase (real or threatened) in tarrifs for that countries home market etc.

7 Here we are making the implicit assumption that cross shareholding between firms does not eliminate the direct incentive for firms to undertake FDI as initially expressed in (1). In the simulations that follow we check that this assumption is valid.

8 We assume that the information allows for the reduction in fixed entry costs. This allows us to model the equilibria in each (sub)game as stationary.

${ }^{9}$ Clearly similar firms may learn more from each other than dissimilar firms will. However, there are common problems such as learning to deal with a foreign legal system and foreign labour markets and practices that are common to all. We thus abstract from differential learning in this paper.
} 


$$
C(t)=\left\{\begin{array}{l}
C^{*} \text { which must be common across firms } \\
C^{* *} \text { if no private information is revealed at } t^{*} \\
\bar{C}^{* *} \text { if the entrant at } t^{*} \text { reveals private information } \\
C^{* * *} \text { if no private information is revealed at } t^{* *} \\
\bar{C}^{* * *} \text { if the entrant at } t^{* *} \text { reveals private information }
\end{array}\right\} \forall t \leq t^{*}
$$

The firms maximize expected profits net of switching costs, which involves each selecting probabilities of FDI at each point in time given those selected by the other firms. We write the probability of firm $n$ switching to FDI as $\rho_{n}$. Since this is a game in stages we also require notation for which firm(s) have already carried out FDI and which have not, consequently $G_{n, i, j}$, will indicate the game where no entry has yet occurred, $G_{n, i}$ the (sub) game where firms $n$ and $i$ have not yet entered, and $G_{n}$ will be the (sub)game where only firm $n$ has not entered. With this notation probabilities will be written in the form $\rho_{n}\left(G_{n, i}\right)$ and so on ${ }^{10}$

The value that a firm obtains from a particular action $(F$ or $D)$ in the game and each sub-game, given the actions of the other firms, will be defined in the form ${ }^{11}$

$$
V^{1}\left(D D D \mid G_{1,2,3}\right)
$$

This is the value to firm 1 of the action $D$ if both other firms also choose $D$ in the game $G_{1,2,3}$. In a similar vein $V^{3}\left(F F D \mid G_{2,3}\right)$ would represent the value to firm 3 of the action $F$ in the subgame $G_{2,3}$, and so on. ${ }^{12}$

\footnotetext{
10 Since each (sub)game is a stationary we do not need any further notation to denote time.

11 Details in the appendix.

12 Hereafter we shall maintain the assumptions

$$
V^{n}\left(F F F \mid G_{n}\right)<V^{n}\left(D F F \mid G_{n}\right) \forall n
$$
}

which are required to ensure that the whole structure does not unravel backwards with all firms entering instantaneously at the first opportunity. 


\subsection{The Extensive Form of the Game.}

We are now ready to describe how the process of FDI evolves by presenting the game in extensive form. Figure 1 illustrates the initial situation faced by the three firms.

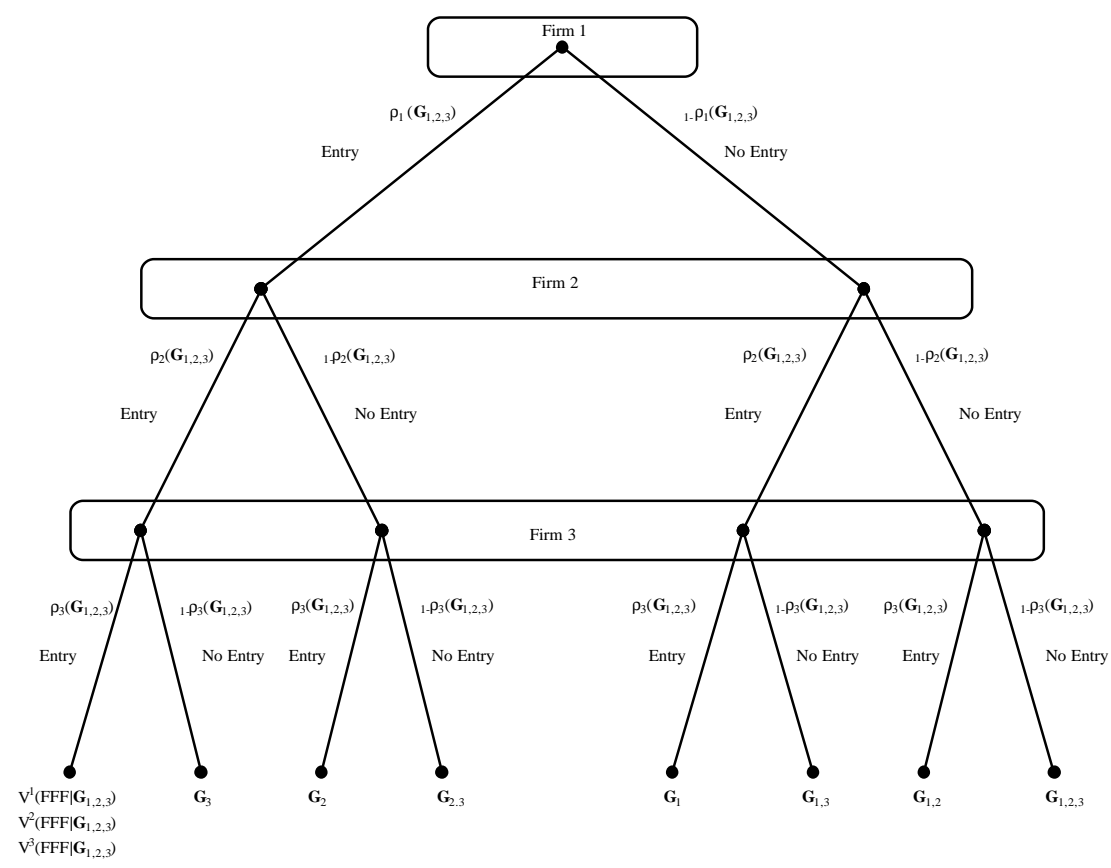

Figure 1: The three firm entry game $G_{1,2,3}$ in extensive form.

Each firm must choose an entry probability, $\rho_{n}\left(G_{1,2,3}\right)$, as a best reply to those chosen by the other two firms. Once a firm (or firms) has entered we move to the appropriate subgame. For example, if firm 1 enters then firms 2 and 3 play the subgame $G_{2,3}$ illustrated in figure 2 


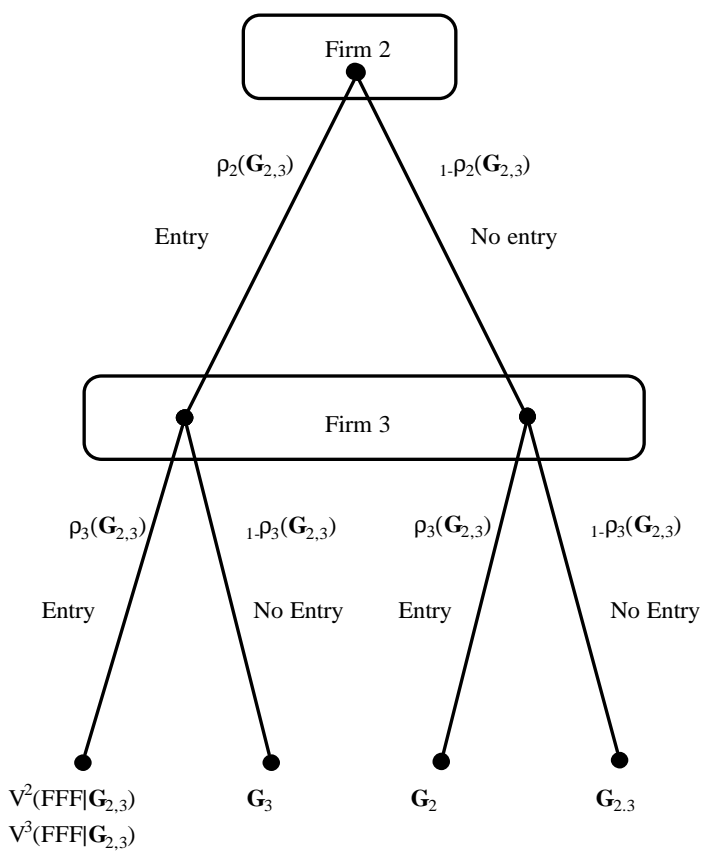

Figure 2: The two firm entry game, $G_{2,3}$ in extensive form.

Here the remaining two firms must choose as best replies the entry probabilities $\rho_{2}\left(G_{2,3}\right)$, and $\rho_{3}\left(G_{2,3}\right)$.

\subsection{Equilibrium.}

To obtain the equilibrium of the model we solve recursively for equilibria in each of the potential subgames, starting with $\left\{G_{1}, G_{2}, G_{3}\right\}$ then using these values to solve $\left\{G_{1,2}, G_{1,3}, G_{2,3}\right\}$, and finally using the values from both $\left\{G_{1}, G_{2}, G_{3}\right\}$ and $\left\{G_{1,2}, G_{1,3}, G_{2,3}\right\}$ to solve for $G_{1,2,3}$. We thus obtain the subgame perfect equilibrium as a sequence of mixed strategy equilibria in the subgames. Given that firms 1 and 2 are, by assumption, members of a symmetric keiretsu, and we have assumed symmetry between these two firms in all other respects, it seems natural to consider symmetric equilibria where $\rho_{1}\left(G_{1,2,3}\right)=\rho_{2}\left(G_{1,2,3}\right) \equiv \rho_{12}\left(G_{1,2,3}\right)$.

While the model is solved in the standard recursive manner we shall present our results, somewhat unconventionally, in their chronological order. This, we feel, aids the intuitive understanding of the problem and allows a better integration of the theory and evidence. 


\subsubsection{The First Wave: Entry in the Game $G_{1,2,3}$.}

Entry in the first wave, as inspection of figures 1 and 2 might suggest, is very complex, if no firm has entered at a time $t$ then there are 8 possible strategy choices leading to 8 possible subgames. The mixed strategy equilibrium for $G_{1,2,3}$ is characterized by 6 conditions. For each firm $n$ we may define a value for the game and an indifference condition that states the firm is indifferent between FDI and domestic production. For firms 1 or 2 these conditions take the form

$$
\begin{aligned}
& \rho_{12}\left(G_{1,2,3}\right)\left[\rho_{3}\left(G_{1,2,3}\right) V^{1}\left(F F F \mid G_{1,2,3}\right)+\left(1-\rho_{3}\left(G_{1,2,3}\right)\right) V^{1}\left(F F D \mid G_{1,2,3}\right)\right] \\
+ & \left(1-\rho_{12}\left(G_{1,2,3}\right)\right)\left[\rho_{3}\left(G_{1,2,3}\right) V^{1}\left(F D F \mid G_{1,2,3}\right)+\left(1-\rho_{3}\left(G_{1,2,3}\right)\right) V^{1}\left(F D D \mid G_{1,2,3}\right)\right] \\
= & \rho_{12}\left(G_{1,2,3}\right)\left[\rho_{3}\left(G_{1,2,3}\right) V^{1}\left(D F F \mid G_{1,2,3}\right)+\left(1-\rho_{3}\left(G_{1,2,3}\right)\right) V^{1}\left(D F D \mid G_{1,2,3}\right)\right] \\
+ & \left(1-\rho_{12}\left(G_{1,2,3}\right)\right)\left[\rho_{3}\left(G_{1,2,3}\right) V^{1}\left(D D F \mid G_{1,2,3}\right)+\left(1-\rho_{3}\left(G_{1,2,3}\right)\right) V^{1}\left(D D D \mid G_{1,2,3}\right)\right]
\end{aligned}
$$

and

$$
\begin{gathered}
V^{1}\left(D D D \mid G_{1,2,3}\right)=\rho_{12}\left(G_{1,2,3}\right)^{2}\left[\rho_{3}\left(G_{1,2,3}\right) V^{1}\left(F F F \mid G_{1,2,3}\right)+\left(1-\rho_{3}\left(G_{1,2,3}\right)\right) V^{1}\left(F F D \mid G_{1,2,3}\right)\right] \\
+\rho_{12}\left(G_{1,2,3}\right)\left(1-\rho_{12}\left(G_{1,2,3}\right)\right)\left[\rho_{3}\left(G_{1,2,3}\right) V^{1}\left(F D F \mid G_{1,2,3}\right)+\left(1-\rho_{3}\left(G_{1,2,3}\right)\right) V^{1}\left(F D D \mid G_{1,2,3}\right)\right] \\
+\left(1-\rho_{12}\left(G_{1,2,3}\right)\right) \rho_{12}\left(G_{1,2,3}\right)\left[\rho_{3}\left(G_{1,2,3}\right) V^{1}\left(D F F \mid G_{1,2,3}\right)+\left(1-\rho_{3}\left(G_{1,2,3}\right)\right) V^{1}\left(D F D \mid G_{1,2,3}\right)\right] \\
+\left(1-\rho_{12}\left(G_{1,2,3}\right)\right)^{2}\left[\rho_{3}\left(G_{1,2,3}\right) V^{1}\left(D D F \mid G_{1,2,3}\right)+\left(1-\rho_{3}\left(G_{1,2,3}\right)\right) V^{1}\left(D D D \mid G_{1,2,3}\right)\right]
\end{gathered}
$$

similar conditions hold for firm 3. Substituting in and solving these equations (together with the firm 3 conditions-see appendix 3) yields solutions

$$
\begin{gathered}
\rho_{1}\left(G_{1,2,3}\right)=\rho_{2}\left(G_{1,2,3}\right)=\psi\left(C^{*}, C^{* *}, r, \beta, \Pi_{D F F}^{1}, \Pi_{F D F}^{1}, \Pi_{F F F}^{1}\right) \\
\rho_{3}\left(G_{1,2,3}\right)=\chi\left(C^{*}, C^{* *}, \bar{C}^{* *}, r, \beta, \Pi_{D F F}^{1}, \Pi_{F D F}^{1}, \Pi_{F F F}^{1}\right) .
\end{gathered}
$$

Details of the form of these expressions are provided in appendix 3. The solutions are very complex and do not easily yield analytical results, thus we resort to numerical method to explore their properties. 
Variations in the Level of Cooperation and Initial Cost of Entry. Tables 1 and 2 provide illustrative examples of simulations run using Mathematica ${ }^{13}$.

\begin{tabular}{|c|c|c|c|c|c|c|c|}
\hline & \multicolumn{6}{|c|}{ Level of Cooperation $\beta$} \\
\hline & & 0.0 & 0.1 & 0.2 & 0.3 & 0.4 & 0.5 \\
\hline \multirow[b]{2}{*}{ Initial Entry } & 0.13 & $\begin{array}{l}0.798548 \\
0.767037\end{array}$ & $\begin{array}{l}0.802769 \\
0.646013\end{array}$ & $\begin{array}{c}0.806623 \\
0.54338\end{array}$ & $\begin{array}{l}0.810167 \\
0.460451\end{array}$ & $\begin{array}{l}0.813446 \\
0.388207\end{array}$ & $\begin{array}{l}0.816497 \\
0.326359\end{array}$ \\
\hline & 0.135 & $\begin{array}{c}0.741582 \\
0.6998\end{array}$ & $\begin{array}{l}0.746784 \\
0583694\end{array}$ & $\begin{array}{l}0.751541 \\
0.487346\end{array}$ & $\begin{array}{l}0.755922 \\
0.407335\end{array}$ & $\begin{array}{l}0.759982 \\
0.341211\end{array}$ & $\begin{array}{l}0.763763 \\
0.287216\end{array}$ \\
\hline \multirow[t]{2}{*}{ Cost $C^{*}$ as a } & 0.14 & $\begin{array}{l}0.66667 \\
0.583333\end{array}$ & $\begin{array}{l}0.676945 \\
0.466752\end{array}$ & $\begin{array}{l}0.685852 \\
0.382626\end{array}$ & $\begin{array}{l}0.693713 \\
0.320238\end{array}$ & $\begin{array}{l}0.700746 \\
0.273668\end{array}$ & $\begin{array}{l}0.707107 \\
0.239369\end{array}$ \\
\hline & 0.145 & $\begin{array}{l}0.589226 \\
0.457293 \\
\end{array}$ & $\begin{array}{l}0.604204 \\
0.353279 \\
\end{array}$ & $\begin{array}{l}0.616748 \\
0.286554 \\
\end{array}$ & $\begin{array}{r}0.62755 \\
0.242181 \\
\end{array}$ & $\begin{array}{l}0.637038 \\
0.213166 \\
\end{array}$ & $\begin{array}{l}0.645497 \\
0.195799 \\
\end{array}$ \\
\hline of $\frac{\Pi_{F D D}^{1}}{r}$ & 0.15 & $\begin{array}{c}0.5 \\
0.277778 \\
\end{array}$ & $\begin{array}{l}0.521899 \\
0.209411 \\
\end{array}$ & $\begin{array}{l}0.539345 \\
0.174076 \\
\end{array}$ & $\begin{array}{l}0.553894 \\
0.156032 \\
\end{array}$ & $\begin{array}{l}0.566391 \\
0.149584 \\
\end{array}$ & $\begin{array}{r}0.57735 \\
0.152197 \\
\end{array}$ \\
\hline
\end{tabular}

Table 1 - The response of first wave entry probabilities of keiretsu firms, $\rho_{12}$, (top cell entry) and non-keiretsu firms, $\rho_{3}$, (bottom cell entry) to variations in the level of cooperation $\beta$, and initial entry $\operatorname{costs} C^{*}$

We see from table 1 that an increase in the level of cooperation, $\beta$, between keiretsu firms increases the first wave entry probabilities of keiretsu firms and lowers the entry probabilities of non-keiretsu firms ${ }^{14}$. The intuition behind these results is complex. Changes in $\beta$ effect the entry probabilities both in the first wave entry game, and the subsequent second wave entry subgames. Recall that in a mixed strategy equilibrium the entry probabilities are determined by the requirement that each firm be indifferent between undertaking FDI and continuing with domestic production. When $\beta$ increases the keiretsu firms individually find FDI less attractive in each subgame. This is because an entrant shares a greater proportion of the benefits from entry with its keiretsu partner, and

\footnotetext{
${ }^{13}$ For the simulation we assumed that $\pi_{F D D}=100, \pi_{F D F}=\pi_{F F D}=96, \pi_{F F F}=90$,

$\pi_{D D D}=89, \pi_{D D F}=\pi_{D F D}=84, \pi_{D F F}=79, r=5 \%$.

For variations in the fixed cost of initial entry we maintained the differntial betwen initial and subseqent entry costs by imposing the same changes on $C^{* *}$ and $\bar{C}^{* *}$.

The properties of the results reported were generally not sensitive to variations parameter values that satisfied the restrictions of the theory.

14 It might appear that the first column in table 1 for $\beta=0$ reveals an inconsistency in the results. This is not the case. The simulations were carried out assuming that keiretsu firms share all private information (not $\beta$ percent of it) thus the entry probabilites should only be equal when $\beta=0$ and $C^{* *}-\bar{C}^{* *}$. Inspection of table 2 demonstrates that this consistency check is satisfied.
} 
also shares a greater proportion of the losses its entry imposes on its partner. So to maintain the keiretsu firms indifference condition the probability of initial entry by the non-keiretsu firm must decline. Similarly for the keiretsu firms the probability of initial entry must increase to keep the non-keiretsu firm indifferent between FDI and domestic production. Here the agrument is even more complex. An increase in $\beta$ makes the non-keiretsu firm less likely to enter in each subsequent subgame (see the next section for details), the relative value of entry to the non-keiretsu firm in the initial game thus increases. Hence, to maintain indifference for the non-keiretsu firm the probability of entry by the keiretsu firms must increase.

Increases in intitial entry costs lower the probabilities of entry for both keiretu and nonkeiretsu firms ${ }^{15}$. Here, in equilibrium, both the keiretsu firms and the non-keiretsu firm must have lower entry probabilites if they are to remain indifferent between FDI and continued domestic production.

\footnotetext{
15 These results obtained for "almost all" the parameter space. For high costs of initial entry, such that the probability of entry by keiretsu firms became very small (in the neighborhood of $\rho_{12} \rightarrow 0.001$ ), the entry probabilities for the non-keiretsu firms became "eratic". We believe this reflects a highly sensitive trade-off, as the keiretsu firm's entry probabilities become very small there is a significant incentive for the non-keiretsu firm to enter, but at the same time the high costs that induced this behavior from the keiretsu firms also provides a strong disincentive to entry for the non-keiretsu firm.
} 
Variations in the Level of Cooperation and the Value of Private Information. Table

2 characterizes our simulation results

\begin{tabular}{|c|c|c|c|c|c|c|c|}
\hline & & \multicolumn{6}{|c|}{ Level of Cooperation $\beta$} \\
\hline & & 0.0 & 0.1 & 0.2 & 0.3 & 0.4 & 0.5 \\
\hline Value of private & 0.0 & $\begin{array}{l}0.66667 \\
0.66667\end{array}$ & $\begin{array}{l}0.676945 \\
0.547127\end{array}$ & $\begin{array}{l}0.685852 \\
0.449485\end{array}$ & $\begin{array}{l}0.693713 \\
0.367889\end{array}$ & $\begin{array}{l}0.700746 \\
0.298665\end{array}$ & $\begin{array}{l}0.707107 \\
0.239369\end{array}$ \\
\hline information & 1.0 & $\begin{array}{c}0.66667 \\
0.645833\end{array}$ & $\begin{array}{l}0.676945 \\
0.526354\end{array}$ & $\begin{array}{l}0.685852 \\
0.431788\end{array}$ & $\begin{array}{c}0.693713 \\
0.35505\end{array}$ & $\begin{array}{l}0.700746 \\
0.291839\end{array}$ & $\begin{array}{l}0.707107 \\
0.239369\end{array}$ \\
\hline$C^{* *}-\bar{C}^{* *}$ & 2.0 & $\begin{array}{c}0.66667 \\
0.625\end{array}$ & $\begin{array}{l}0.676945 \\
0.506044\end{array}$ & $\begin{array}{l}0.685852 \\
0.414771\end{array}$ & $\begin{array}{c}0.693713 \\
0.34286\end{array}$ & $\begin{array}{l}0.700746 \\
0.285421\end{array}$ & $\begin{array}{l}0.707107 \\
0.239369\end{array}$ \\
\hline as a percentage & 3.0 & $\begin{array}{c}0.66667 \\
0.604167\end{array}$ & $\begin{array}{l}0.676945 \\
0.486181\end{array}$ & $\begin{array}{l}0.685852 \\
0.398395\end{array}$ & $\begin{array}{c}0.693713 \\
0.33127\end{array}$ & $\begin{array}{l}0.700746 \\
0.279374\end{array}$ & $\begin{array}{l}0.707107 \\
0.239369\end{array}$ \\
\hline of $\frac{\Pi_{F D D}^{1}}{r}$ & 4.0 & $\begin{array}{l}0.66667 \\
0.58333\end{array}$ & $\begin{array}{l}0.676945 \\
0.466752\end{array}$ & $\begin{array}{l}0.685852 \\
0.382626\end{array}$ & $\begin{array}{l}0.693713 \\
0.320238\end{array}$ & $\begin{array}{l}0.700746 \\
0.273668\end{array}$ & $\begin{array}{l}0.707107 \\
0.239369\end{array}$ \\
\hline
\end{tabular}

Table 2 - The response of first wave entry probabilities of keiretsu firms (top cell entry) $\rho_{12}$ and non-keiretsu firms (bottom cell entry), $\rho_{3}$, to variations in the level of cooperation between keiretsu firms and the value of private information.

Despite their apparent complexity the properties of the equilibria may be quite easily stated. Increases in the value of private information $C^{* *}-\bar{C}^{* *}$, generated by varying $\bar{C}^{* *}$ for a given $C^{* *}$, lower the probability of entry by non-keiretsu firms at all levels of the cooperation parameter, and do not effect the probability of entry by the keiretsu firms. Here again the intuition is subtle and follows from understanding the nature of a mixed strategy equilibrium. An increase in $C^{* *}-\bar{C}^{* *}$ makes it more attractive for each keiretsu firm to delay initial entry in anticipation that the other will enter and provide them with this reduction in entry cost. Thus, for the keiretsu firms to remain indifferent between FDI and domestic production the probability of entry by the non-keiretsu firm must fall. The invariance of the keiretsu firm's entry probabilities arrises because variations in $\bar{C}^{* *}$ do not effect the payoffs associated with FDI for the non-keiretsu firm, and since the probabilities of entry by the keiretsu firms are determined by the condition that the non-keiretsu firm is indifferent between FDI and domestic production it then follows that the 
probability of entry by the keiretsu firms is unaffected by variations in $\bar{C}^{* *} \cdot{ }^{16}$. Notice also that for all values of $\beta>0$ and $C^{* *}-\bar{C}^{* *}$ the probability of entry by each keiretsu firm is larger than for the non-keiretsu firm. Our results are illustrated in figure 3
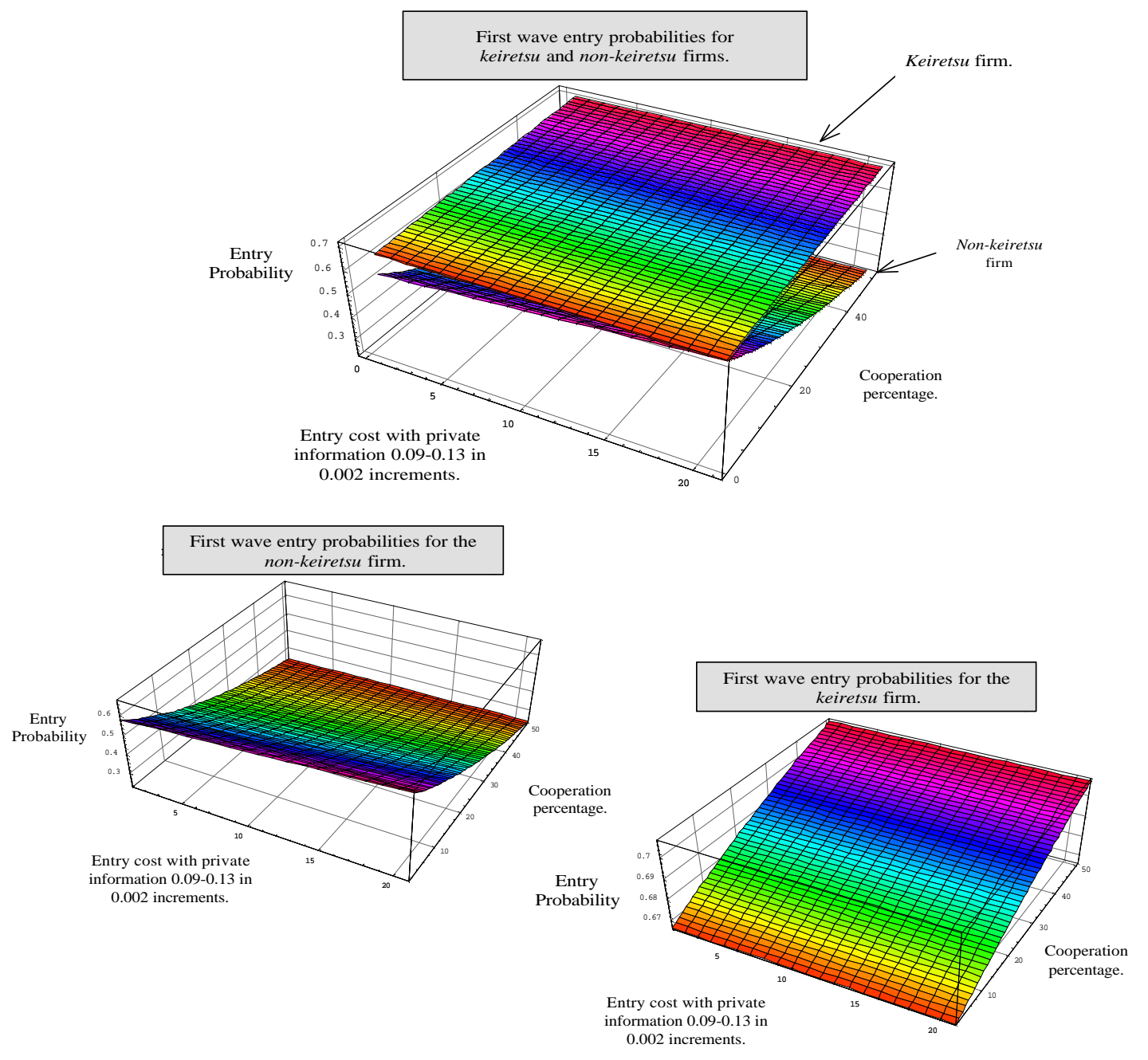

Figure 3.

\footnotetext{
16 The results reported were found to be very robust and obtained over all of the parameter space for which mixed strategy equilibria were found to exist. Full details and the simulation programs are available from the authors on request.
} 


\subsubsection{The Second Wave: Entry in the Subgames $G_{1,2}, G_{2,3}$, and $G_{1,3}$.}

We term the subgames $G_{1,2}, G_{2,3}$, and $G_{1,3}$ as the second wave of entry. Here one firm has entered and the remaining two firms enjoy the information generated by the first entrant. In the games $G_{2,3}$, and $G_{1,3}$ prior entry was by a keiretsu member, the remaining keiretsu firm enjoys the entry cost reduction $C^{*}-\bar{C}^{* *}$ which reflects both the public and private information, where as the cost reduction for the non-keiretsu firm is only $C^{*}-C^{* *}$ reflecting only the publicly available information. In the game $G_{1,2}$ the non-keiretsu firm has entered and only reveals the public information, giving the cost reduction $C^{*}-C^{* *}$. As before the equilibria in these subgames are derived from a value for the subgame and an indifference condition for each of the two firms. ${ }^{17}$ For example, in the subgame $G_{2,3}$ (and by symmetry $G_{1,3}$ ) these involve four expressions ${ }^{18}$. The two indifference conditions

$$
\begin{aligned}
& \rho_{2}\left(G_{2,3}\right) V^{3}\left(F F F \mid G_{2,3}\right)+\left(1-\rho_{2}\left(G_{2,3}\right)\right) V^{3}\left(F F D \mid G_{2,3}\right) \\
= & \rho_{2}\left(G_{2,3}\right) V^{3}\left(D F F \mid G_{2,3}\right)+\left(1-\rho_{2}\left(G_{2,3}\right)\right) V^{3}\left(D F D \mid G_{2,3}\right)
\end{aligned}
$$

and

$$
\begin{aligned}
& \rho_{3}\left(G_{2,3}\right) V^{2}\left(F F F \mid G_{2,3}\right)+\left(1-\rho_{3}\left(G_{2,3}\right)\right) V^{2}\left(F D F \mid G_{2,3}\right) \\
= & \rho_{3}\left(G_{2,3}\right) V^{2}\left(D F F \mid G_{2,3}\right)+\left(1-\rho_{3}\left(G_{2,3}\right)\right) V^{2}\left(D D F \mid G_{2,3}\right)
\end{aligned}
$$

and the two value functions

$$
\begin{gathered}
\left.V^{2}\left(D D F \mid G_{2,3}\right)=\rho_{2}\left(G_{2,3}\right)\left[\rho_{3}\left(G_{2,3}\right) V^{2}\left(F F F \mid G_{2,3}\right)\right)+\left(1-\rho_{3}\left(G_{2,3}\right)\right) V^{2}\left(F D F \mid G_{2,3}\right)\right] \\
+\left(1-\rho_{2}\left(G_{2,3}\right)\right)\left[\rho_{3}\left(G_{2,3}\right) V^{2}\left(D F F \mid G_{2,3}\right)+\left(1-\rho_{3}\left(G_{2,3}\right)\right) V^{2}\left(D D F \mid G_{2,3}\right)\right]
\end{gathered}
$$

\footnotetext{
17 Details in appendix 2.

${ }^{18}$ In each of these subgames, for there to be a mixed strategy equilibria we require that for each firm neither $F$ nor $D$ is a dominant strategy. Consistent with our prior assumptions we assume that each firm prefers to enter if the other does not, but both prefer not to enter if the other does. Again using the subgame $G_{2,3}$ to fix notation this translates into conditions of the form

$$
V^{2}\left(F D F \mid G_{2,3}\right)>V^{2}\left(D D F \mid G_{2,3}\right) \geq V^{2}\left(D F F \mid G_{2,3}\right)>V^{2}\left(F F F \mid G_{2,3}\right)
$$
}


and

$$
\begin{gathered}
\left.V^{3}\left(D F D \mid G_{2,3}\right)=\rho_{3}\left(G_{2,3}\right)\left[\rho_{2}\left(G_{2,3}\right) V^{3}\left(F F F \mid G_{2,3}\right)\right)+\left(1-\rho_{2}\left(G_{2,3}\right)\right) V^{3}\left(F F D \mid G_{2,3}\right)\right] \\
\quad+\left(1-\rho_{3}\left(G_{2,3}\right)\right)\left[\rho_{2}\left(G_{2,3}\right) V^{3}\left(D F F \mid G_{2,3}\right)+\left(1-\rho_{2}\left(G_{2,3}\right)\right) V^{3}\left(D F D \mid G_{2,3}\right)\right]
\end{gathered}
$$

Substituting in and solving, then repeating the process for the other subgames provides the solu-

\begin{tabular}{|c|c|c|c|}
\hline \multirow[b]{2}{*}{ Firm } & \multicolumn{3}{|c|}{ Subgame. } \\
\hline & \multicolumn{2}{|l|}{$G_{1,2}$} & $G_{2,3}$ \\
\hline \multirow{2}{*}{1} & $(1-2 \beta)\left(\frac{\Pi_{D F F}^{1}}{r}-\frac{\Pi_{F D F}^{1}}{r}+C^{* *}\right)$ & $\underline{\Pi_{D F F}^{1}}-\frac{\Pi_{F D F}^{1}}{1}+C^{* *}$ & \multirow{2}{*}{$\mathrm{N} / \mathrm{A}$} \\
\hline & $\frac{\Pi_{F F F}^{1}}{r}-(1-\beta) \frac{\Pi_{F D F}^{1}}{r}-\beta \frac{\Pi_{D F F}^{1}}{r}-\beta C^{* *}$ & $\frac{\Pi_{F F F}^{1}}{r}-\frac{\Pi_{F D F}^{1}}{r}$ & \\
\hline \multirow{2}{*}{2} & $(1-2 \beta)\left(\frac{\Pi_{D F F}^{1}}{r}-\frac{\Pi_{F D F}^{1}}{r}+C^{* *}\right)$ & \multirow{2}{*}{$\mathrm{N} / \mathrm{A}$} & $\Pi_{D F E}^{1}-\frac{\Pi_{F D E}^{1}}{+C^{* *}}$ \\
\hline & $\frac{\Pi_{F F F}^{1}}{r}-(1-\beta) \frac{\Pi_{F D F}^{1}}{r}-\beta \frac{\Pi_{D F F}^{1}}{r}-\beta C^{* *}$ & & $\frac{\Pi_{F F F}^{1}-\frac{\Pi_{F D F}^{1}}{r}}{r}$ \\
\hline \multirow{2}{*}{3} & \multirow{2}{*}{$\mathrm{N} / \mathrm{A}$} & $(1-\beta)\left(\frac{\Pi_{D F F}^{1}}{r}-\frac{\Pi_{F F D}^{1}}{r}+\bar{C}^{* *}\right)$ & $(1-\beta)\left(\frac{\Pi_{D F F}^{1}}{r}-\frac{\Pi_{F F D}^{1}}{r}+\bar{C}^{* *}\right)$ \\
\hline & & $\frac{\Pi_{F F F}^{1}}{F}-\frac{\Pi_{F F D}^{1}}{r}$ & $\frac{\Pi_{F F F}^{1}}{F r}-\frac{\Pi_{F F D}^{1}}{r}$ \\
\hline
\end{tabular}
tions

Table 3: Equilibrium entry probabilities for the Second Wave subgames.

It is now straightforward to derive the comparative statics properties of these subgames,

\begin{tabular}{|c|c|c|c|c|c|c|}
\hline \multirow{2}{*}{} & \multicolumn{6}{|c|}{ Entry Probabilities } \\
\cline { 2 - 7 } & \multicolumn{7}{|c|}{ Subgame } \\
\hline & \multicolumn{7}{|c|}{$G_{1,2}$} & \multicolumn{2}{|c|}{$G_{1,3}$} & \multicolumn{2}{c|}{$G_{2,3}$} \\
\hline$d \beta$ & - & - & 0 & - & 0 & - \\
\hline$d \rho_{1}\left(G_{1,2}\right)$ & $d \rho_{2}\left(G_{1,2}\right)$ & $d \rho_{1}\left(G_{1,3}\right)$ & $d \rho_{3}\left(G_{1,3}\right)$ & $d \rho_{2}\left(G_{2,3}\right)$ & $d \rho_{3}\left(G_{2,3}\right)$ \\
\hline$d C^{* *}$ & $-a$ & $-a$ & - & 0 & - & 0 \\
\hline & 0 & 0 & 0 & - & 0 & - \\
\hline \multicolumn{7}{|c|}{$a:$ For $\frac{\Pi_{F D F}^{1}}{r}-\frac{\Pi_{D F F}^{1}}{r} \geq C^{* *}$} \\
\hline \multicolumn{7}{|c|}{ Table 4: Comparative statics for the Second Wave entry probabilities. } \\
\hline
\end{tabular}


We see that in the interesting subgames $G_{1,3}$ and $G_{2,3}$ (the ones that will be the focus of our empirical analysis), those where a mix of keiretsu and non-keiretsu firms remain, an increase in the keiretsu cooperation parameter $d \beta>0$ lowers the probability of entry by non-keiretsu firms, but does not effect the keiretsu firms, thus making the relative probability of entry by keiretsu members higher. This follows immediately from the nature of the mixed strategy equilibrium, the probabilities $\rho_{3}\left(G_{1,3}\right)$ and $\rho_{3}\left(G_{2,3}\right)$ must satisfy the indifference conditions for the keiretsu firms. As the parameter $\beta$ increases the entering keiretsu firm shares more of the gain from entry with the keiretsu firm that had previously entered, and also shares more of the losses its entry imposes on this firm. Thus the returns to entry for the new entrant are reduced, to maintain indifference it is necessary then that the non-keiretsu firm's probability of entry declines. For the interesting subgames, the effects of changes in the cost parameters $d C^{* *}$ and $d \bar{C}^{* *}$ may be explained in a similar manner. As $C^{* *}$ increases the value of entry to the non-keiretsu firm declines, so to maintain the indifference condition the entry probability of the appropriate keiretsu firm must fall. As $\bar{C}^{* *}$ increases the value of entry to the appropriate keiretsu firm declines, so to maintain the indifference condition of the mixed strategy equilibrium the entry probability of the non-keiretsu firm must fall. Notice also that since $d \rho_{3}\left(G_{1,3}\right) / d \beta<0$ and $d \rho_{3}\left(G_{2,3}\right) / d \beta<0$ and both $\rho_{1}\left(G_{1,3}\right)=\rho_{3}\left(G_{1,3}\right)$ and $\rho_{2}\left(G_{2,3}\right)=\rho_{3}\left(G_{2,3}\right)$ if $\beta=0$ each keiretsu firm always has a higher probability of FDI than the non-keiretsu firm. In the subgame $G_{1,2}$ only keiretsu firms remain and only non-keiretsu firms have entered. The effects of $\beta$ on entry probabilities are explained by the dilution of entry incentives as discussed for the other subgames. The effects of $C^{* *}$ are again determined be the mixed strategy indifference conditions as above. That $\bar{C}^{* *}$ does not effect keiretsu entry probabilities follows from the fact that the only prior entrant was not a keiretsu member and does not share any private cost reducing information. 


\section{Empirical Analysis.}

The previous section presents a game-theoretic model that yields predictions about firm-level FDI probabilities that depend on whether a firm belongs to a keiretsu group or not, the strength of private information sharing within these keiretsu groups, and the degree of cooperation through overlapping ownership shares. Exact tests of the model's predictions are impossible given data availability and the (un)observability of the model's exogenous parameters, such as the degree of information sharing amongst firms. In addition, the model is a simple representation of a more complicated reality that features thousands of Japanese firms and dozens of different keiretsu affiliations. Nevertheless, we think it is important to examine whether data on FDI decisions by Japanese firms are supportive of the model and its predictions. The data we can observe and collect is FDI entry patterns by Japanese firms, their keiretsu affiliations, and some measures of the strength of those keiretsu affiliations. Thus, in this section we estimate firm-level probabilities of FDI by Japanese manufacturing firms to examine whether keiretsu affiliations affects these probabilities in ways that are broadly consistent with the model's predictions.

\subsection{Empirical Methodology.}

The basic framework we use is a probit regression that estimates the probability of FDI by Japanese firm $(i)$ in country $(j)$ in a particular period. Firm $(i)$ invests in country $(j)$ if it is a profitable decision, which depends on a number of exogenous factors. We do not observe the profitability of the FDI decision $\left(P_{i j}^{*}\right)$, but do observe whether the firm engages in FDI or not $\left(F D I_{i j}\right)$, as well as relevant exogenous factors $\left(X_{i j}\right)$. Thus, we formulate a standard probit regression framework:

$$
\begin{gathered}
P_{i j}^{*}=\beta^{\prime} X_{i j}+u_{i j}, \\
F D I_{i j}=1 \text { if } P_{i j}^{*}>0, \text { and } F D I_{i j}=0 \text { otherwise, }
\end{gathered}
$$

where $u_{i j}$ is an assumed standard normal error term and $\beta$ is a vector of parameters that we estimate. 
Previous work on the relationship between keiretsu affiliations and FDI decisions has used a similar probit framework to analyze samples comprised of Japanese firms with and without keiretsu affiliations. The approach is to examine whether there is a positive correlation between a dummy variable, indicating whether a firm is a member of a keiretsu or not, and the firm's FDI decision. In other words, the regressor matrix, $X_{i j}=\left[K E I R_{i}, Z_{i j}\right]$, where $K E I R_{i}$ represents the "keiretsu or not" dummy variable, and Zij represents other firm- and country-level exogenous factors that affect the profitability of the FDI decision. Thus, the question examined by these studies is whether there is something inherent about membership in any keiretsu that makes FDI more likely for a particular firm, ceteris paribus. Typically, the underlying hypothesis is that the source of this positive keiretsu effect could be due to a variety of sources, including lower capital costs and information sharing. However, as noted in the paper's introduction, the previous studies have generally found mixed evidence of a positive statistically-significant keiretsu effect.

The theoretical model presented in the previous section has shown that the role of keiretsu affiliations on FDI decisions is likely much more complicated than the model underlying the hypothesis tested by previous work. In other words, previous empirical work has been mis-specified, which may be the main reason for the inconclusive results. The main insight from our theory is that the keiretsu effect on FDI decisions is not necessarily an independent one as modeled by previous work. Instead, the keiretsu effect on one firm's FDI decision depends on FDI decisions (actual or potential) made by other firms in its own keiretsu and by firms that are not in its own keiretsu. This can be particularly seen in the subgames $G_{1,3}, G_{1,2}$ and $G_{2,3}$ of our theoretical model, which we describe as the second wave of entry, and where the effect of keiretsu membership on a firm's FDI decision works through firms' investment decisions in the previous period. For this reason, we focus on examining second-period predictions.

In order to identify the information and cooperation effects of keiretsu affiliations on FDI in subsequent (or "second wave") period, we examine interactions between the "keiretsu or not" dummy variable and previous investment by other firms. In fact, the most interesting second- 
period predictions we obtain in our theoretical model are the effects on a remaining keiretsu firm and non-keiretsu firm when a keiretsu firm entered in the first period, the subgames $G_{1,3}$ and $G_{2,3}$. This implies the following regressor matrix to test the effects of keiretsu affiliations on subsequent FDI decisions:

$$
X_{i j}=\left[K E I R_{i} * P F D I_{-} K_{i j}, N O N K E I R_{i} * P F D I_{-} K_{j}, Z_{i j}\right]
$$

where $N O N K E I R_{i}=\left(1-K E I R_{i}\right), P F D I \_K_{j}$ is previous investment by all relevant keiretsuaffiliated Japanese firms in country $j$, and $P F D I \_K_{i j}$ is previous FDI by firm $i$ 's keiretsu-member firms in countr $j$. The first term captures the effect of previous investment of keiretsu members in a country on a keiretsu firm's FDI decision into the same country. The second term captures the effect of previous investment by keiretsu firms in a country on a non-keiretsu firm's decision to invest in the same country. As indicated by the theory, if keiretsu affiliation leads to substantial entry cost savings from information sharing, we expect a positive coefficient on the first term indicating an increase in a keiretsu firm's second-period entry probability when there has been previous entry by member firms of its keiretsu. It should have no impact on the non-keiretsu firm's entry probability. On the other hand, the cooperation effect of keiretsu membership will tend to decrease the probability of subsequent entry by the non-keiretsu firm, while having no impact on the keiretsu-firm's entry probability.

Again, the keiretsu effects we wish to uncover with this empirical specification are those that jointly depend on previous investment by keiretsu firms, not independent effects of keiretsu membership on FDI entry decisions, such as those due to advantageous costs of capital. However, in the estimates below we also include a "keiretsu or not" dummy variable separately as a control regressor to examine whether these independent effects are also an important factor in firms' FDI decisions. In addition, following previous literature, we include firm size and previous investment by the firm in the country as controls. Firm size (assets measured in millions of yen) is expected to 
have a positive coefficient as it proxies for the level of firm-specific assets held by the firm which, by the internalization hypothesis leads to greater FDI. ${ }^{19}$ Previous FDI by the firm is another source of information and learning by the firm that should increase the likelihood of FDI.

\subsection{Data.}

We use information from Japanese Overseas Investment, 1992/93 (English version) published by Toyo Keizai Inc., for data on Japanese FDI. ${ }^{20}$ This publication reports information from a census of all Japanese-owned subsidiaries, and includes location, parent firm(s), establishment dates, employment, and type of investment (greenfield or acquisition). These data are updated and published semiannually. However, with the exception of the 1984 report, no other years provide an English version. The 1992/93 census comes at the end of a substantial wave of FDI activity by Japanese firms in general, which began in the mid-1980s and subsided in the early 1990s. This is an important consideration in matching the theoretical predictions from the previous section with what we observe in the data. In the theory we present there is a well-defined initial period in which all firms are deciding whether to engage in FDI for the first time, and a single, well-defined subsequent period. In reality, it is difficult to identify periods of initial entry and subsequent entry. Initial FDI by Japanese manufacturing firms into foreign countries began sporadically in the 1960s and 1970s. Thus, it seems plausible to treat any period since then as representing behavior of firms in a period subsequent to initial entry. However, there have also been substantial ebbs and flows of outward Japanese FDI activity. This suggests it is reasonable to think of the beginning of a new wave of outward FDI activity in the mid-1980s as an "initial" entry period, with investment in later years of the wave as "subsequent" entry.

As a result, we examine 1990/91 FDI-entry probabilities of Japanese firms across nine major

\footnotetext{
${ }^{19}$ We tried other more direct proxies of firm-specific assets, R\&D expenditures and R\&D intensity (R\&D expenditures divided by firm size), as control regressors. However, these variables are highly correlated with firm size, are always statistically insignificant, and lead to a significant number of lost observations due to missing data. Their inclusion does not impact our main results in any way.

${ }^{20}$ We gratefully thank Keith Head and John Ries at the University of British Columbia for sharing their electronic version of these data.
} 
destination countries as a function of FDI entry patterns in the destination market in the preceding three years, 1987 through $1989 .{ }^{21}$ The dependent variable is defined as whether a firm engages in FDI in a country in 1990/91 or not. The previous investment measures in our regressor set are defined in terms of number of new employees (in thousands) in the 1987-1989 period.

Similar to previous studies, we sample firms from the industrial and electrical machinery industries, because there is adequate frequency of FDI activity across firms in these industries and the variability of keiretsu affiliations is relatively high for these industries as well. We then matched these firms to keiretsu groupings using Industrial Groupings in Japan 1988/89 published by Dodwell Marketing Consultants. ${ }^{22}$ In addition to listing firms' keiretsu affiliations, this publication also assigns an index of the firm's "inclination" to its keiretsu which takes values of 1,2,3, or 4. Data on firm size (i.e., total assets) are taken from the 1990 edition of the Japan Company Handbook published by Toyo Keizai Inc.

\subsection{Results.}

Column 1 of table 3 presents estimates from a base scenario where we specify the probability of entry by a Japanese firm as a function of only its size in assets, previous FDI by the same firm in the same country, and the firm's strength of keiretsu inclination. The probit regression pools observations of FDI activity across all firms and major destination countries in our sample. This specification is closest to that found in previous literature and will serve as a basis for comparison with our other estimates. We obtain positive coefficients on all three regressors, as expected. Interestingly, the keiretsu inclination variable is statistically significant, which is not always true with previous empirical findings. This suggests that keiretsu affiliation has an independent impact on FDI probabilities, which may due to a variety of explanations, such as

\footnotetext{
21 The top nine destination countries are Indonesia, the Philippines, Malaysia, Singapore, South Korea, Taiwan, Thailand, the United Kingdom, the United States, and West Germany.

22 There are eight major industrial groupings listed by the Dodwell Marketing Consultants: DKB, Fuyo, IBJ, Mitsui, Mitsubishi, Sanwa, Sumitomo, and Tokai. In addition, a significant number of our sample's firms (12\%) belonged to smaller groupings centered around a major electronics or automotive company: Hitachi, Toshiba-IHI, Toyota, and Nissan. In our sample, $45 \%$ of the firms belonged to one of these keiretsu groupings, while the others were considered non-affiliated.
} 
lower costs of capital discussed earlier. The firm's size is also highly significant, as will be the case with all our regressions.

\begin{tabular}{|c|c|c|c|c|c|}
\hline Regressors & (1) & (2) & $(3)$ & $(4)$ & (5) \\
\hline $\begin{array}{c}\text { Previous FDI by firm's } \\
\text { own keiretsu }\end{array}$ & & $\begin{array}{c}0.185^{* * *} \\
(0.055) \\
\end{array}$ & $\begin{array}{c}0.192^{* *} \\
(0.083) \\
\end{array}$ & $\begin{array}{l}0.130^{*} \\
(0.067)\end{array}$ & $\begin{array}{c}0.209^{* *} \\
(0.096)\end{array}$ \\
\hline $\begin{array}{l}\text { Previous FDI by keiretsu firms } \\
* \text { Firm is not in keiretsu }\end{array}$ & & $\begin{array}{l}0.013 \\
(0.013) \\
\end{array}$ & $\begin{array}{l}0.015 \\
(0.014) \\
\end{array}$ & $\begin{array}{c}-0.022 \\
(0.022)\end{array}$ & $\begin{array}{c}0.050^{* *} \\
(0.025)\end{array}$ \\
\hline Keiretsu inclination & $\begin{array}{c}0.090^{* *} \\
(0.036)\end{array}$ & $\begin{array}{l}0.065 \\
(0.045)\end{array}$ & $\begin{array}{l}0.060 \\
(0.057)\end{array}$ & $\begin{array}{c}-0.020 \\
(0.073)\end{array}$ & $\begin{array}{c}0.140^{* *} \\
(0.069)\end{array}$ \\
\hline Previous FDI by firm i in country $j$ & $\begin{array}{l}0.058 \\
(0.045) \\
\end{array}$ & $\begin{array}{l}0.044 \\
(0.047) \\
\end{array}$ & $\begin{array}{c}-0.002 \\
(0.056) \\
\end{array}$ & $\begin{array}{c}-0.037 \\
(0.072) \\
\end{array}$ & $\begin{array}{l}0.096 \\
(0.062) \\
\end{array}$ \\
\hline Firm size (assets in millions of yen) & $\begin{array}{c}0.335^{* * *} \\
(0.069) \\
\end{array}$ & $\begin{array}{c}0.380^{* *} \\
(0.070)\end{array}$ & $\begin{array}{c}0.507^{* * *} \\
(0.095)\end{array}$ & $\begin{array}{c}0.572^{* * *} \\
(0.125) \\
\end{array}$ & $\begin{array}{c}0.257^{* * *} \\
(0.089)\end{array}$ \\
\hline Chi-squared measure of fitness & $65.61^{* * *}$ & $79.24^{* * *}$ & $49.61^{* * *}$ & $40.04^{* * *}$ & $36.84^{* * *}$ \\
\hline Pseudo $\mathrm{R}^{2}$ & 0.09 & 0.11 & 0.08 & 0.13 & 0.11 \\
\hline Number of Observations & 2295 & 2295 & 2007 & 765 & 1530 \\
\hline $\begin{array}{l}\text { Table 5: Probit re } \\
\text { najor destination count }\end{array}$ & sions o & $\begin{array}{l}\text { panese } \\
\text { tandar }\end{array}$ & I decisic & in & \\
\hline
\end{tabular}

Column 2 of table 5 shows probit estimates when we include the variables of interest suggested by this paper's theoretical analysis: interactions of previous investment by keiretsu firms interacted with dummies indicating whether firm is in the same keiretsu or not. The coefficient estimates on these focus regressors reveal an interesting pattern that sheds light on the channels through which keiretsu affiliations affect FDI decisions. In particular, the effect of previous FDI in a country by keiretsu-member firms has a strong positive effect on a keiretsu firm's probability of FDI to the same country. This provides evidence that keiretsu firms obtain entry cost advantages from information sharing that occurs between them and the firms in their own keiretsu that have already invested in a country. Calculation of the marginal effects on entry probabilities at the means of our regressors also shows that this statistically significant effect has economic significance as well. In fact, a standard deviation increase in previous FDI by the firm's own keiretsu members in a country (334 additional employees) leads to a $0.6 \%$ increase in a keiretsu firm's subsequent FDI 
probability at the means. With an average subsequent FDI probability of $2.9 \%$ in our sample, this means there is a $22 \%$ increase in the keiretsu firm's likelihood of FDI.

On the other hand, there is little evidence that cooperation (or profit-sharing) motives affect FDI probabilities. The theory suggests that this cooperation channel would lead to a negative effect of previous keiretsu FDI on non-keiretsu firms' entry probability, while our coefficient estimate is positive and statistically insignificant. While the independent effect of keiretsu affiliation was significantly positive in our column 1 regressors, its coefficient falls and is no longer statistically significant at standard confidence levels. In addition, our model which includes the keiretsu interaction terms clearly outperforms the modle in column 1 that only includes keiretsu affiliation as an independent factor in FDI probabilities. Finally, size of the firm continues to have a strong and statistically significant positive correlation with FDI likelihood.

One concern with the estimates in columns 1 and 2 of table 5 may be the inclusion of keiretsu affiliations which are centered around a major electronics or automotive firm, rather than a major bank. These keiretsus often have vertical integration features to them, as many of the keiretsu firms are input suppliers to the main firm. It's possible that our strong positive correlation between previous keiretsu investment and a keiretsu firm's subsequent FDI probability is biased upward due to economic incentives for suppliers to follow the downstream firm rather than the effects of information sharing on entry decisions. As indicated in footnote $21,12 \%$ of our sample's firms are in these vertical keiretsus. To gauge the sensitivity of our estimates to this issue, column 3 of table 5 reports coefficient estimates when we eliminate observations of firms in vertical keiretsus from our sample. This change in our sample has no significant impact on our coefficient estimates, and, in particular, the coefficient on the effect of previous keiretsu FDI on a keiretsu firm's subsequent FDI probability goes up slightly and remains statistically significant.

A second issue is whether the impact of previous FDI on firms' subsequent FDI probabilities depends on the destination country. For example, motives for investment by Japanese firms into less-developed countries may be more concerned with outsourcing, whereas motives for invest- 
ment into other industrialized countries, such as the United States, may be more concerned with market access. There may also be more uncertainty and/or risk associated with investment in less-developed countries. Columns 4 and 5 of table 5 , present coefficient estimates of our regression model for separate samples of FDI into industrialized countries (the United States, United Kingdom, and West Germany) and less-developed countries (Indonesia, Korea, Malaysia, the Philippines, Singapore, Taiwan, and Thailand). The general results hold for both samples though there are some differences. For both samples, previous keiretsu FDI leads to higher subsequent FDI probability for a keiretsu firm, though the coefficient is almost twice as large in the lessdeveloped country sample. This may suggest that information-sharing is much more important for lowering subsequent entry costs of keiretsu members in less-developed countries. The effect of previous keiretsu FDI on subsequent non-keiretsu FDI probability is positive in the less-developed country sample, though the estimated magnitude fairly small. The only other significant difference between the two samples is that the independent impact of keiretsu affiliation is significant for FDI into less-developed countries, but not for FDI into industrialized countries. If this regressor is capturing cost of capital advantages of keiretsus, a possible explanation is the home country (Japanese) sources of financing may be much more important for FDI into less-developed countries.

There were other sensitivity tests we conducted that had no qualitative impact on our coefficient estimates. First, we also used counts of FDI occurrences to construct our measures of previous FDI, but obtained similar coefficient signs to those reported in table 3 using employment measures. We also estimated coefficients using a Poisson model, rather than probit, and obtained qualitatively identical results. Finally, we specified our dependent variable in employees and used a tobit specification with truncation at zero, and obtained qualitatively identical results.

In summary, our estimates suggest that information-sharing advantages that occur in keiretsus once member firms have invested in a country has a substantial impact on subsequent FDI probabilities by other keiretsu-member firms. There is little evidence that cooperation structures (e.g., 
from cross-ownership and profit-sharing arrangements) impact FDI probabilities in substantial ways. One explanation is that cross-ownership between the keiretsu firms and the main keiretsu bank tend to be much larger than that among the keiretsu manufacturing firms themselves. Finally, the evidence for independent effects of keiretsu affiliations becomes weak once we control for keiretsu effects through previous FDI decisions within the keiretsu, except in the case of Japanese FDI investment into less-developed countries.

\section{Conclusions.}

We have developed and empirically investigated a model of strategic FDI. Our focus has been on the role of industrial ownership structure in determining FDI probabilities. Our theoretical model suggests two main mechanisms by which ownership structures matter for FDI entry probabilites. First, there are direct incentive effects working through the interactions of firms on input and output markets and the sharing of the profits genarated. Second, there are indirect incentive effects working through the role of initial entry in generating information valuable in reducing subsequent entry costs. Our empirical work suggests that this second information effect is of greater importance than the direct incentive effects induced by overlapping ownership structures. This does not say that overlapping ownership structures do not matter, but rather tells us that their main effect is through the incentives to generate and share information relevent to the costs of undertaking FDI. 


\section{Appendices.}

\subsection{Appendix 1 - Derivation of the value functions for the sub-games $G_{1}, G_{2}$, and $G_{3}$.}

We derive the value functions $V^{3}\left(F F F \mid G_{3}\right)$ and $V^{3}\left(D F F \mid G_{3}\right), V^{1}\left(F F F \mid G_{1}\right), V^{1}\left(D F F \mid G_{1}\right)$, and $V^{2}\left(F F F \mid G_{2}\right), V^{2}\left(D F F \mid G_{2}\right)$ may be obtained in an identical fashion.

$$
V^{3}\left(F F F \mid G_{3}\right) \equiv \int_{t=0}^{\infty}\left[\left(1-\sum_{i=1,2} \beta_{3}^{i}\right)\left[\Pi_{F F F}^{3}-K^{* * *}\right]+\beta_{1}^{3} \Pi_{F F F}^{1}+\beta_{2}^{3} \Pi_{F F F}^{2}\right] e^{-r t} d t
$$

integrating the RHS of this expression gives us

$$
V^{3}\left(F F F \mid G_{3}\right) \equiv\left(1-\sum_{i=1,2} \beta_{3}^{i}\right)\left[\frac{\Pi_{F F F}^{3}}{r}-K^{* * *}\right]+\beta_{1}^{3} \frac{\Pi_{F F F}^{1}}{r}+\beta_{2}^{3} \frac{\Pi_{F F F}^{2}}{r}
$$

where $K^{* * *}=C^{* * *}$ or $\bar{C}^{* * *}$ as appropriate.

$$
\begin{gathered}
V^{3}\left(D F F \mid G_{3}\right) \equiv \int_{t=}^{\infty}\left[\left(1-\sum_{i=1,2} \beta_{3}^{i}\right) \Pi_{D F F}^{3}+\beta_{1}^{3} \Pi_{F F D}^{1}+\beta_{2}^{3} \Pi_{F D F}^{2}\right] e^{-r t} d t \\
=\left(1-\sum_{i=1,2} \beta_{3}^{i}\right) \frac{\Pi_{D F F}^{3}}{r}+\beta_{1}^{3} \frac{\Pi_{F F D}^{1}}{r}+\beta_{2}^{3} \frac{\Pi_{F D F}^{2}}{r}
\end{gathered}
$$

\subsection{Appendix 2 - Derivation of the Equilibrium Mixed Strategy Entry Probabilities for the Subgames $G_{1,2}, G_{2,3}$, and $G_{1,3}$.}

\subsubsection{Subgame $G_{1,2}$.}

For this subgame we utilize the expressions for the value of the (sub)game and the indifference conditions to solve for the entry probabilities as

$$
\begin{aligned}
& \rho_{12}\left(G_{1,2}\right) V^{1}\left(F F F \mid G_{1,2}\right)+\left(1-\rho_{12}\left(G_{1,2}\right)\right) V^{1}\left(F D F \mid G_{1,2}\right) \\
= & \rho_{12}\left(G_{1,2}\right) V^{1}\left(D F F \mid G_{1,2}\right)+\left(1-\rho_{12}\left(G_{1,2}\right)\right) V^{1}\left(D D F \mid G_{1,2}\right)
\end{aligned}
$$

and

$$
\begin{gathered}
\left.V^{1}\left(D D F \mid G_{1,2}\right)=\rho_{12}\left(G_{1,2}\right)^{2} V^{1}\left(F F F \mid G_{1,2}\right)\right)+\rho_{12}\left(G_{1,2}\right)\left(1-\rho_{12}\left(G_{1,2}\right)\right) V^{1}\left(F D F \mid G_{1,2}\right) \\
+\left(1-\rho_{12}\left(G_{1,2}\right)\right) \rho_{12}\left(G_{1,2}\right) V^{1}\left(D F F \mid G_{1,2}\right)+\left(1-\rho_{12}\left(G_{1,2}\right)\right)^{2} V^{1}\left(D D F \mid G_{1,2}\right)
\end{gathered}
$$


Multiplying through the indifference condition by $\rho_{12}\left(G_{1,2}\right)$ then manipulating the two expressions reveals

$$
V^{1}\left(D F F \mid G_{1,2}\right)=V^{1}\left(D D F \mid G_{1,2}\right)
$$

substituting this back into the indifference condition and solving provides

$$
\rho_{12}\left(G_{1,2}\right)=\frac{V^{1}\left(D F F \mid G_{1,2}\right)-V^{1}\left(F D F \mid G_{1,2}\right)}{V^{1}\left(F F F \mid G_{1,2}\right)-V^{1}\left(F D F \mid G_{1,2}\right)}
$$

substituting in for the terms

$$
\begin{aligned}
& V^{1}\left(D F F \mid G_{1,2}\right)=(1-\beta) \frac{\Pi_{D F F}^{1}}{r}+\beta\left(\frac{\Pi_{F F D}^{2}}{r}-C^{* *}\right)=(1-\beta) \frac{\Pi_{D F F}^{1}}{r}+\beta\left(\frac{\Pi_{F D F}^{1}}{r}-C^{* *}\right) \\
& V^{1}\left(F D F \mid G_{1,2}\right)=(1-\beta)\left(\frac{\Pi_{F D F}^{1}}{r}-C^{* *}\right)+\beta \frac{\Pi_{D F F}^{2}}{r}=(1-\beta)\left(\frac{\Pi_{F D F}^{1}}{r}-C^{* *}\right)+\beta \frac{\Pi_{D F F}^{1}}{r}
\end{aligned}
$$

and

$$
V^{1}\left(F F F \mid G_{1,2}\right)=(1-\beta)\left(\frac{\Pi_{F F F}^{1}}{r}-C^{* *}\right)+\beta\left(\frac{\Pi_{F F F}^{2}}{r}-C^{* *}\right)=\frac{\Pi_{F F F}^{1}}{r}-\bar{C}^{* *}
$$

provides

$$
\rho_{12}\left(G_{1,2}\right)=\frac{(1-2 \beta)\left(\frac{\Pi_{D F F}^{1}}{r}-\frac{\Pi_{F D F}^{1}}{r}+C^{* *}\right)}{\frac{\Pi_{F F F}^{2}}{r}-(1-\beta) \frac{\Pi_{F D F}^{1}}{r}-\beta \frac{\Pi_{D F F}^{1}}{r}-\beta C^{* *}}
$$

as reported in the text.

\subsubsection{Subgame $G_{2,3}$.}

From the text we have the equations for the values of the game

$$
\begin{aligned}
& \left.V^{2}\left(D D F \mid G_{2,3}\right)=\rho_{2}\left(G_{2,3}\right) \rho_{3}\left(G_{2,3}\right) V^{2}\left(F F F \mid G_{2,3}\right)\right)+\rho_{2}\left(G_{2,3}\right)\left(1-\rho_{3}\left(G_{2,3}\right)\right) V^{2}\left(F D F \mid G_{2,3}\right) \\
& \quad+\left(1-\rho_{2}\left(G_{2,3}\right)\right) \rho_{3}\left(G_{2,3}\right) V^{2}\left(D F F \mid G_{2,3}\right)+\left(1-\rho_{2}\left(G_{2,3}\right)\right)\left(1-\rho_{3}\left(G_{2,3}\right)\right) V^{2}\left(D D F \mid G_{2,3}\right) \\
& \left.V^{3}\left(D F D \mid G_{2,3}\right)=\rho_{2}\left(G_{2,3}\right) \rho_{3}\left(G_{2,3}\right) V^{3}\left(F F F \mid G_{2,3}\right)\right)+\rho_{3}\left(G_{2,3}\right)\left(1-\rho_{2}\left(G_{2,3}\right)\right) V^{3}\left(F F D \mid G_{2,3}\right) \\
& \quad+\left(1-\rho_{3}\left(G_{2,3}\right)\right) \rho_{3}\left(G_{2,3}\right) V^{3}\left(D F F \mid G_{2,3}\right)+\left(1-\rho_{3}\left(G_{2,3}\right)\right)\left(1-\rho_{2}\left(G_{2,3}\right)\right) V^{3}\left(D F D \mid G_{2,3}\right)
\end{aligned}
$$


and the indifference conditions

$$
\begin{gathered}
\rho_{2}\left(G_{2,3}\right) V^{3}\left(F F F \quad \mid G_{2,3}\right)+\left(1-\rho_{2}\left(G_{2,3}\right)\right) V^{3}\left(F F D \mid G_{2,3}\right) \\
=\rho_{2}\left(G_{2,3}\right) V^{3}\left(D F F \mid G_{2,3}\right)+\left(1-\rho_{2}\left(G_{2,3}\right)\right) V^{3}\left(D F D \mid G_{2,3}\right) \\
\rho_{3}\left(G_{2,3}\right) V^{2}\left(F F F \mid G_{2,3}\right)+\left(1-\rho_{3}\left(G_{2,3}\right)\right) V^{2}\left(F D F \mid G_{2,3}\right) \\
=\rho_{3}\left(G_{2,3}\right) V^{2}\left(D F F \mid G_{2,3}\right)+\left(1-\rho_{3}\left(G_{2,3}\right)\right) V^{2}\left(D D F \mid G_{2,3}\right)
\end{gathered}
$$

multiplying the indifference conditions by $\rho_{3}\left(G_{2,3}\right)$ and $\rho_{2}\left(G_{2,3}\right) \rho_{2}\left(G_{2,3}\right)$ respectively yields

$$
\begin{aligned}
& \rho_{3}\left(G_{2,3}\right) \rho_{2}\left(G_{2,3}\right) V^{3}\left(F F F \mid G_{2,3}\right)+\rho_{3}\left(G_{2,3}\right)\left(1-\rho_{2}\left(G_{2,3}\right)\right) V^{3}\left(F F D \mid G_{2,3}\right) \\
= & \rho_{3}\left(G_{2,3}\right) \rho_{2}\left(G_{2,3}\right) V^{3}\left(D F F \mid G_{2,3}\right)+\rho_{3}\left(G_{2,3}\right)\left(1-\rho_{2}\left(G_{2,3}\right)\right) V^{3}\left(D F D \mid G_{2,3}\right) \\
& \rho_{2}\left(G_{2,3}\right) \rho_{3}\left(G_{2,3}\right) V^{2}\left(F F F \mid G_{2,3}\right)+\rho_{2}\left(G_{2,3}\right)\left(1-\rho_{3}\left(G_{2,3}\right)\right) V^{2}\left(F D F \mid G_{2,3}\right) \\
= & \rho_{2}\left(G_{2,3}\right) \rho_{3}\left(G_{2,3}\right) V^{2}\left(D F F \mid G_{2,3}\right)+\rho_{2}\left(G_{2,3}\right)\left(1-\rho_{3}\left(G_{2,3}\right)\right) V^{2}\left(D D F \mid G_{2,3}\right)
\end{aligned}
$$

substitution the RHS of these expressions into the values of the game gives

$$
\begin{gathered}
V^{2}\left(D D F \mid G_{2,3}\right)=\rho_{2}\left(G_{2,3}\right) \rho_{3}\left(G_{2,3}\right) V^{2}\left(D F F \mid G_{2,3}\right)+\rho_{2}\left(G_{2,3}\right)\left(1-\rho_{3}\left(G_{2,3}\right)\right) V^{2}\left(D D F \mid G_{2,3}\right) \\
\quad+\left(1-\rho_{2}\left(G_{2,3}\right)\right) \rho_{3}\left(G_{2,3}\right) V^{2}\left(D F F \mid G_{2,3}\right)+\left(1-\rho_{2}\left(G_{2,3}\right)\right)\left(1-\rho_{3}\left(G_{2,3}\right)\right) V^{2}\left(D D F \mid G_{2,3}\right) \\
V^{3}\left(D F D \mid G_{2,3}\right)=\rho_{3}\left(G_{2,3}\right) \rho_{2}\left(G_{2,3}\right) V^{3}\left(D F F \mid G_{2,3}\right)+\rho_{3}\left(G_{2,3}\right)\left(1-\rho_{2}\left(G_{2,3}\right)\right) V^{3}\left(D F D \mid G_{2,3}\right) \\
\quad+\left(1-\rho_{3}\left(G_{2,3}\right)\right) \rho_{3}\left(G_{2,3}\right) V^{3}\left(D F F \mid G_{2,3}\right)+\left(1-\rho_{3}\left(G_{2,3}\right)\right)\left(1-\rho_{2}\left(G_{2,3}\right)\right) V^{3}\left(D F D \mid G_{2,3}\right)
\end{gathered}
$$

simplifying these reduce to

$$
\begin{aligned}
& V^{2}\left(D D F \mid G_{2,3}\right)=V^{2}\left(D F F \mid G_{2,3}\right) \\
& V^{3}\left(D F D \mid G_{2,3}\right)=V^{3}\left(D F F \mid G_{2,3}\right)
\end{aligned}
$$


using this information the indifference conditions may be rewritten

$$
\begin{aligned}
& \rho_{3}\left(G_{2,3}\right) V^{2}\left(F F F \mid G_{2,3}\right)+\left(1-\rho_{3}\left(G_{2,3}\right)\right) V^{2}\left(F D F \mid G_{2,3}\right) \\
= & \rho_{3}\left(G_{2,3}\right) V^{2}\left(D F F \mid G_{2,3}\right)+\left(1-\rho_{3}\left(G_{2,3}\right)\right) V^{2}\left(D F F \mid G_{2,3}\right) \\
& \rho_{2}\left(G_{2,3}\right) V^{3}\left(F F F \mid G_{2,3}\right)+\left(1-\rho_{2}\left(G_{2,3}\right)\right) V^{3}\left(F F D \mid G_{2,3}\right) \\
= & \rho_{2}\left(G_{2,3}\right) V^{3}\left(D F F \mid G_{2,3}\right)+\left(1-\rho_{2}\left(G_{2,3}\right)\right) V^{3}\left(D F F \mid G_{2,3}\right)
\end{aligned}
$$

rewriting these in terms of $\rho_{2}\left(G_{2,3}\right)$ and $\rho_{3}\left(G_{2,3}\right)$ gives

$$
\begin{aligned}
& \rho_{2}\left(G_{2,3}\right)=\frac{V^{3}\left(D F F \mid G_{2,3}\right)-V^{3}\left(F F D \mid G_{2,3}\right)}{\left.V^{3}\left(F F F \mid G_{2,3}\right)-V^{3}\left(F F D \mid G_{2,3}\right)\right)} \\
& \rho_{3}\left(G_{2,3}\right)=\frac{V^{2}\left(D F F \mid G_{2,3}\right)-V^{2}\left(F D F \mid G_{2,3}\right)}{\left.V^{2}\left(F F F \mid G_{2,3}\right)-V^{2}\left(F D F \mid G_{2,3}\right)\right)}
\end{aligned}
$$

now

- $V^{3}\left(D F F \mid G_{2,3}\right)=\frac{\Pi_{D F F}^{3}}{r}$,

- $\left(F F D \mid G_{2,3}\right)=\frac{\Pi_{F F D}^{3}}{r}-C^{* *}$, and

- $V^{3}\left(F F F \mid G_{2,3}\right)=\frac{\Pi_{F F F}^{3}}{r}-C^{* *}$, so

$$
\rho_{2}\left(G_{2,3}\right)=\frac{\frac{\Pi_{D F F}^{3}}{r}-\frac{\Pi_{F F D}^{3}}{r}+C^{* *}}{\frac{\Pi_{F F F}^{3}}{r}-C^{* *}-\frac{\Pi_{F F D}^{3}}{r}+C^{* *}}=\frac{\Pi_{D F F}^{3}-\Pi_{F F D}^{3}+r C^{* *}}{\Pi_{F F F}^{3}-\Pi_{F F D}^{3}}
$$

further

- $V^{2}\left(D F F \mid G_{2,3}\right)=(1-\beta) \frac{\Pi_{D F F}^{2}}{r}+\beta \frac{\Pi_{F D F}^{1}}{r}$,

- $V^{2}\left(F D F \mid G_{2,3}\right)=(1-\beta)\left[\frac{\Pi_{F D F}^{2}}{r}-\bar{C}^{* *}\right]+\beta \frac{\Pi_{F F D}^{1}}{r}$, and 
- $V^{2}\left(F F F \mid G_{2,3}\right)=\frac{\Pi_{F F F}^{3}}{r}-\bar{C}^{* *}$ so

$$
\begin{aligned}
\rho_{3}\left(G_{2,3}\right) & =\frac{V^{2}\left(D F F \mid G_{2,3}\right)-V^{2}\left(F D F \mid G_{2,3}\right)}{V^{2}\left(F F F \mid G_{2,3}\right)-V^{2}\left(F D F \mid G_{2,3}\right)} \\
& =\frac{(1-\beta) \frac{\Pi_{D F F}^{2}}{r}+\beta \frac{\Pi_{F D F}^{1}}{r}-(1-\beta)\left[\frac{\Pi_{F D F}^{2}}{r}-\bar{C}^{* *}\right]-\beta \frac{\Pi_{F F D}^{1}}{r}}{\frac{\Pi_{F F F}^{2}}{r}-(1-\beta) C^{* *}-(1-\beta)\left[\frac{\Pi_{F D F}^{2}}{r}-\bar{C}^{* *}\right]-\beta \frac{\Pi_{F F D}^{1}}{r}} \\
& =\frac{(1-\beta)\left(\frac{\Pi_{D F F}^{1}}{r}-\frac{\Pi_{F D F}^{1}}{r}+\bar{C}^{* *}\right)}{\frac{\Pi_{F F F}^{1}}{r}-\frac{\Pi_{F D F}^{1}}{r}}
\end{aligned}
$$

which are the solutions reported in the text.

\subsubsection{Subgame $G_{1,3}$.}

The solutions for this subgame are derived exactly as in the previous case except firms 2 and 1 change roles, we immediately have

$$
\begin{gathered}
\rho_{1}\left(G_{1,3}\right)=\frac{\frac{\Pi_{D F F}^{3}}{r}-\frac{\Pi_{F F D}^{3}}{r}+C^{* *}}{\frac{\Pi_{F F F}^{3}}{r}-C^{* *}-\frac{\Pi_{F F D}^{3}}{r}+C^{* *}}=\frac{\Pi_{D F F}^{3}-\Pi_{F F D}^{3}+r C^{* *}}{\Pi_{F F F}^{3}-\Pi_{F F D}^{3}} \\
\rho_{3}\left(G_{1,3}\right)=\frac{(1-\beta)\left(\frac{\Pi_{D F F}^{1}}{r}-\frac{\Pi_{F D F}^{1}}{r}+\bar{C}^{* *}\right)}{\frac{\Pi_{F F F}^{1}}{r}-\frac{\Pi_{F D F}^{1}}{r}}
\end{gathered}
$$

\subsection{Appendix 3 - Derivation of the Equilibrium Mixed Strategy Entry Probabilities for the Game $G_{1,2,3}$.}

Exploiting symmetry so $\rho_{12}\left(G_{1,2,3}\right) \equiv \rho_{1}\left(G_{1,2,3}\right)=\rho_{2}\left(G_{1,2,3}\right) \neq \rho_{3}\left(G_{1,2,3}\right)$, we adopt the same method as used in appendix 2 to obtain solution equations for $\rho_{12}\left(G_{1,2,3}\right)$ and $\rho_{3}\left(G_{1,2,3}\right)$ of the form

$$
\begin{gathered}
\left(2-\rho_{12}\left(G_{1,2,3}\right)\right) \rho_{12}\left(G_{1,2,3}\right)^{2} V^{3}\left(F F F \mid G_{1,2,3}\right) \\
+2\left(2-\rho_{12}\left(G_{1,2,3}\right)\right) \rho_{12}\left(G_{1,2,3}\right)\left(1-\rho_{12}\left(G_{1,2,3}\right)\right) V^{3}\left(F F D \mid G_{1,2,3}\right) \\
+\left(2-\rho_{12}\left(G_{1,2,3}\right)\right)\left(1-\rho_{12}\left(G_{1,2,3}\right)\right)^{2} V^{3}\left(F D D \mid G_{1,2,3}\right) \\
-\rho_{12}\left(G_{1,2,3}\right) V^{3}\left(D F F \mid G_{1,2,3}\right)-2\left(1-\rho_{12}\left(G_{1,2,3}\right)\right) V^{3}\left(D F D \mid G_{1,2,3}\right)=0
\end{gathered}
$$




$$
\begin{gathered}
V^{1}\left(F F F \mid G_{1,2,3}\right) \rho_{12}\left(G_{1,2,3}\right) \rho_{3}\left(G_{1,2,3}\right)\left[\rho_{12}\left(G_{1,2,3}\right) \rho_{3}\left(G_{1,2,3}\right)-\rho_{12}\left(G_{1,2,3}\right)-\rho_{3}\left(G_{1,2,3}\right)\right] \\
+V^{1}\left(F F D \mid G_{1,2,3}\right) \rho_{12}\left(G_{1,2,3}\right)\left[1-\rho_{3}\left(G_{1,2,3}\right)\right]\left[\rho_{12}\left(G_{1,2,3}\right) \rho_{3}\left(G_{1,2,3}\right)-\rho_{12}\left(G_{1,2,3}\right)-\rho_{3}\left(G_{1,2,3}\right)\right] \\
+V^{1}\left(F D F \mid G_{1,2,3}\right)\left[1-\rho_{12}\left(G_{1,2,3}\right]\right) \rho_{3}\left(G_{1,2,3}\right)\left[\rho_{12}\left(G_{1,2,3}\right) \rho_{3}\left(G_{1,2,3}\right)-\rho_{12}\left(G_{1,2,3}\right)-\rho_{3}\left(G_{1,2,3}\right)\right] \\
+V^{1}\left(F D D \mid G_{1,2,3}\right)\left[1-\rho_{12}\left(G_{1,2,3}\right)\right]\left[1-\rho_{3}\left(G_{1,2,3}\right)\right]\left[\rho_{12}\left(G_{1,2,3}\right) \rho_{3}\left(G_{1,2,3}\right)-\rho_{12}\left(G_{1,2,3}\right)-\rho_{3}\left(G_{1,2,3}\right)\right] \\
+V^{1}\left(D F F \mid G_{1,2,3}\right) \rho_{12}\left(G_{1,2,3}\right) \rho_{3}\left(G_{1,2,3}\right)+V^{1}\left(D F D \mid G_{1,2,3}\right) \rho_{12}\left(G_{1,2,3}\right)\left[1-\rho_{3}\left(G_{1,2,3}\right)\right] \\
+V^{1}\left(D D F \mid G_{1,2,3}\right)\left[1-\rho_{12}\left(G_{1,2,3}\right)\right] \rho_{3}\left(G_{1,2,3}\right)=0
\end{gathered}
$$

We Derive first the expression for $\rho_{12}\left(G_{1,2,3}\right)$ and thus need to obtain expressions for

- $V^{3}\left(F F F \mid G_{1,2,3}\right)=\frac{\Pi_{F F F}^{3}}{r}-C^{*}$

- $V^{3}\left(F F D \mid G_{1,2,3}\right)=\frac{\Pi_{F F D}^{3}}{r}-C^{*}$

- $V^{3}\left(F D D \mid G_{1,2,3}\right)=V^{3}\left(F D D \mid G_{1,2}\right)-C^{*}$

- $V^{3}\left(D F F \mid G_{1,2,3}\right)=\frac{\Pi_{D F F}^{3}}{r}$

- $V^{3}\left(D F D \mid G_{1,2,3}\right)=V^{3}\left(D F D \mid G_{2,3}\right)$

It now follows that we need to obtain $V^{3}\left(F D D \mid G_{1,2}\right)$ and $V^{3}\left(D F D \mid G_{2,3}\right)$ from the appropriate subgames

The subgame $V^{3}\left(F D D \mid G_{1,2}\right)$

the value to player 3 of this subgame may be written

$$
\begin{aligned}
& \left.V^{3}\left(F D D \mid G_{1,2}\right)=\rho_{1}\left(G_{1,2}\right) \rho_{2}\left(G_{1,2}\right) V^{3}\left(F F F \mid G_{1,2}\right)\right) \\
& \quad+\rho_{1}\left(G_{1,2}\right)\left(1-\rho_{2}\left(G_{1,2}\right)\right) V^{3}\left(F F D \mid G_{1,2}\right) \\
& \quad+\left(1-\rho_{1}\left(G_{1,2}\right)\right) \rho_{2}\left(G_{1,2}\right) V^{3}\left(F D F \mid G_{1,2}\right) \\
& +\left(1-\rho_{1}\left(G_{1,2}\right)\right)\left(1-\rho_{2}\left(G_{1,2}\right)\right) V^{3}\left(F D D \mid G_{1,2}\right)
\end{aligned}
$$


exploiting symmetry and $V^{3}\left(F F D \mid G_{1,2}\right)=V^{3}\left(F D F \mid G_{1,2}\right)$ this reduces to

$$
V^{3}\left(F D D \mid G_{1,2}\right)=\frac{\left.\rho_{12}\left(G_{1,2}\right) V^{3}\left(F F F \mid G_{1,2}\right)\right)+2\left(1-\rho_{12}\left(G_{1,2}\right)\right) V^{3}\left(F F D \mid G_{1,2}\right)}{2-\rho_{12}\left(G_{1,2}\right)}
$$

now

- $V^{3}\left(F F F \mid G_{1,2}\right)=\frac{\Pi_{F F F}^{3}}{r}$

- $V^{3}\left(F F D \mid G_{1,2}\right)=\frac{\Pi_{F F D}^{3}}{r}, \mathrm{so}$

$$
V^{3}\left(F D D \mid G_{1,2}\right)=\frac{\rho_{12}\left(G_{1,2}\right) \frac{\Pi_{F F F}^{3}}{r}+2\left(1-\rho_{12}\left(G_{1,2}\right)\right) \frac{\Pi_{F F D}^{3}}{r}}{2-\rho_{12}\left(G_{1,2}\right)}
$$

from appendix 2 we have

$$
\rho_{12}\left(G_{1,2}\right)=\frac{(1-2 \beta)\left(\frac{\Pi_{D F F}^{1}}{r}-\frac{\Pi_{F D F}^{1}}{r}+C^{* *}\right)}{\frac{\Pi_{F F F}^{2}}{r}-(1-\beta) \frac{\Pi_{F D F}^{1}}{r}-\beta \frac{\Pi_{D F F}^{1}}{r}-\beta C^{* *}}
$$

We may now conclude that

$$
\begin{aligned}
& V^{3}\left(F D D \mid G_{1,2}\right)=\frac{\left(\frac{(1-2 \beta)\left(\frac{\Pi_{D F F}^{1}}{r}-\frac{\Pi_{F D F}^{1}}{r}+C^{* *}\right)}{\frac{\Pi_{F F F}^{2}}{r}-(1-\beta) \frac{\Pi_{F D F}^{1}}{r}-\beta \frac{\Pi_{D F F}^{1}}{r}-\beta C^{* *}}\right) \frac{\Pi_{F F F}^{3}}{r}}{2-\left(\frac{(1-2 \beta)\left(\frac{\Pi_{D F F}^{1}}{r}-\frac{\Pi_{F D F}^{1}}{r}+C^{* *}\right)}{\frac{\Pi_{F F F}^{2}}{r}-(1-\beta) \frac{\Pi_{F D F}^{1}}{r}-\beta \frac{\Pi_{D F F}^{1}}{r}-\beta C^{* *}}\right)}
\end{aligned}
$$

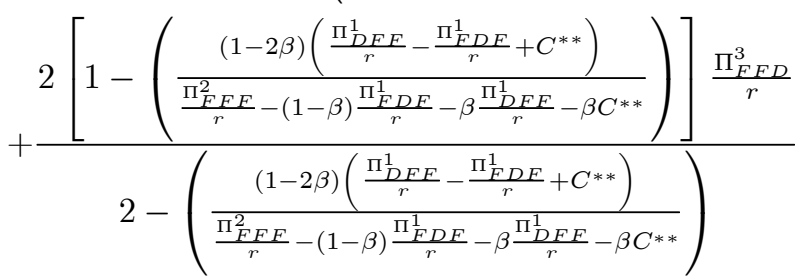

$$
\begin{aligned}
& =\frac{\left(\frac{(1-2 \beta)\left(\frac{\Pi_{D F F}^{1}}{r}-\frac{\Pi_{F D F}^{1}}{r}+C^{* *}\right)}{\frac{\Pi_{F F F}^{2}}{r}-(1-\beta) \frac{\Pi_{F D F}^{1}}{r}-\beta \frac{\Pi_{D F F}^{1}}{r}-\beta C^{* *}}\right) \frac{\Pi_{F F F}^{1}}{r}}{2-\left(\frac{(1-2 \beta)\left(\frac{\Pi_{D F F}^{1}}{r}-\frac{\Pi_{F D F}^{1}}{r}+C^{* *}\right)}{\frac{\Pi_{F F F}^{2}}{r}-(1-\beta) \frac{\Pi_{F D F}^{1}}{r}-\beta \frac{\Pi_{D F F}^{1}}{r}-\beta C^{* *}}\right)} \\
& +\frac{2\left[1-\left(\frac{(1-2 \beta)\left(\frac{\Pi_{D F F}^{1}}{r}-\frac{\Pi_{F D F}^{1}}{r}+C^{* *}\right)}{\frac{\Pi_{F F F}^{2}}{r}-(1-\beta) \frac{\Pi_{F D F}^{1}}{r}-\beta \frac{\Pi_{D F F}^{1}}{r}-\beta C^{* *}}\right)\right] \frac{\Pi_{F D F}^{1}}{r}}{2-\left(\frac{(1-2 \beta)\left(\frac{\Pi_{D F F}^{1}}{r}-\frac{\Pi_{F D F}^{1}}{r}+C^{* *}\right)}{\frac{\Pi_{F F F}^{2}}{r}-(1-\beta) \frac{\Pi_{F D F}^{1}}{r}-\beta \frac{\Pi_{D F F}^{1}}{r}-\beta C^{* *}}\right)}
\end{aligned}
$$


The same techniques yield

$$
V^{3}\left(D F D \mid G_{2,3}\right)=V^{3}\left(D F F \mid G_{2,3}\right)
$$

and again from appendix 2 we have

$$
\rho_{2}\left(G_{2,3}\right)=\frac{\frac{\Pi_{D F F}^{3}}{r}-\frac{\Pi_{F F D}^{3}}{r}+C^{* *}}{\frac{\prod_{F F F}^{3}}{r}-C^{* *}-\frac{\Pi_{F F D}^{3}}{r}+C^{* *}}
$$

and

$$
\rho_{3}\left(G_{2,3}\right)=\frac{(1-\beta)\left(\frac{\Pi_{D F F}^{1}}{r}-\frac{\Pi_{F D F}^{1}}{r}+\bar{C}^{* *}\right)}{\frac{\Pi_{F F F}^{1}}{r}-\frac{\Pi_{F D F}^{1}}{r}}
$$

thus we have all the components reported in the text and used in the numerical simulations.

Now we may derive the expression for $\rho_{3}\left(G_{1,2,3}\right)$ From our prior calculations we have

$$
\begin{gathered}
V^{1}\left(F F F \mid G_{1,2,3}\right) \rho_{12}\left(G_{1,2,3}\right) \rho_{3}\left(G_{1,2,3}\right)\left[\rho_{12}\left(G_{1,2,3}\right) \rho_{3}\left(G_{1,2,3}\right)-\rho_{12}\left(G_{1,2,3}\right)-\rho_{3}\left(G_{1,2,3}\right)\right] \\
+V^{1}\left(F F D \mid G_{1,2,3}\right) \rho_{12}\left(G_{1,2,3}\right)\left[1-\rho_{3}\left(G_{1,2,3}\right)\right]\left[\rho_{12}\left(G_{1,2,3}\right) \rho_{3}\left(G_{1,2,3}\right)-\rho_{12}\left(G_{1,2,3}\right)-\rho_{3}\left(G_{1,2,3}\right)\right] \\
+V^{1}\left(F D F \mid G_{1,2,3}\right)\left[1-\rho_{12}\left(G_{1,2,3}\right]\right) \rho_{3}\left(G_{1,2,3}\right)\left[\rho_{12}\left(G_{1,2,3}\right) \rho_{3}\left(G_{1,2,3}\right)-\rho_{12}\left(G_{1,2,3}\right)-\rho_{3}\left(G_{1,2,3}\right)\right] \\
+V^{1}\left(F D D \mid G_{1,2,3}\right)\left[1-\rho_{12}\left(G_{1,2,3}\right)\right]\left[1-\rho_{3}\left(G_{1,2,3}\right)\right]\left[\rho_{12}\left(G_{1,2,3}\right) \rho_{3}\left(G_{1,2,3}\right)-\rho_{12}\left(G_{1,2,3}\right)-\rho_{3}\left(G_{1,2,3}\right)\right] \\
+V^{1}\left(D F F \mid G_{1,2,3}\right) \rho_{12}\left(G_{1,2,3}\right) \rho_{3}\left(G_{1,2,3}\right)+V^{1}\left(D F D \mid G_{1,2,3}\right) \rho_{12}\left(G_{1,2,3}\right)\left[1-\rho_{3}\left(G_{1,2,3}\right)\right] \\
+V^{1}\left(D D F \mid G_{1,2,3}\right)\left[1-\rho_{12}\left(G_{1,2,3}\right)\right] \rho_{3}\left(G_{1,2,3}\right)=0
\end{gathered}
$$

so we need expressions for

- $V^{1}\left(F F F \mid G_{1,2,3}\right)=(1-\beta)\left(\frac{\Pi_{F F F}^{1}}{r}-C^{*}\right)+\beta\left(\frac{\Pi_{F F F}^{2}}{r}-C^{*}\right)=\frac{\Pi_{F F F}^{1}}{r}-C^{*}$

- $V^{1}\left(F F D \mid G_{1,2,3}\right)=(1-\beta)\left(\frac{\Pi_{F F D}^{1}}{r}-C^{*}\right)+\beta\left(\frac{\Pi_{F D F}^{2}}{r}-C^{*}\right)=\frac{\Pi_{F F D}^{1}}{r}-C^{*}$

- $V^{1}\left(F D F \mid G_{1,2,3}\right)=(1-\beta)\left(\frac{\Pi_{F D F}^{1}}{r}-C^{*}\right)+\beta \frac{\Pi_{D F F}^{2}}{r}$

- $V^{1}\left(F D D \mid G_{1,2,3}\right)=V^{1}\left(F D D \mid G_{2,3}\right)-(1-\beta) C^{*}$

- $V^{1}\left(D F F \mid G_{1,2,3}\right)=(1-\beta) \frac{\Pi_{D F F}^{1}}{r}+\beta\left(\frac{\Pi_{F F D}^{2}}{r}-C^{*}\right)=(1-\beta) \frac{\Pi_{D F F}^{1}}{r}+\beta\left(\frac{\Pi_{F D F}^{1}}{r}-C^{*}\right)$ 
- $V^{1}\left(D F D \mid G_{1,2,3}\right)=V^{1}\left(D F D \mid G_{1,3}\right)-(1-\beta) C^{*}$

- $V^{1}\left(D D F \mid G_{1,2,3}\right)=V^{1}\left(D D F \mid G_{1,2}\right)$

So we need to solve for the values of subgames $V^{1}\left(F D D \mid G_{2,3}\right), V^{1}\left(D F D \mid G_{1,3}\right)$, and $V^{1}\left(D D F \mid G_{1,2}\right)$

The subgame $G_{2,3}$ From prior calculations we have

$$
\begin{gathered}
\rho_{2}\left(G_{2,3}\right)=\frac{\Pi_{D F F}^{3}-\Pi_{F F D}^{3}+r C^{* *}}{\Pi_{F F F}^{3}-\Pi_{F F D}^{3}} \\
\rho_{3}\left(G_{2,3}\right)=\frac{(1-\beta)\left(\frac{\Pi_{D F F}^{1}}{r}-\frac{\Pi_{F D F}^{1}}{r}+\bar{C}^{* *}\right)}{\frac{\Pi_{F F F}^{1}}{r}-\frac{\Pi_{F D F}^{1}}{r}}
\end{gathered}
$$

so

$$
\begin{gathered}
V^{1}\left(F D D \mid G_{1,2,3}\right)=V^{1}\left(F D D \mid G_{2,3}\right)-(1-\beta) C^{*} \\
=\left[\frac{\rho_{2}\left(G_{2,3}\right) \rho_{3}\left(G_{2,3}\right)}{1-\left[1-\rho_{2}\left(G_{2,3}\right)\right]\left[1-\rho_{3}\left(G_{2,3}\right)\right]}\right]\left[\frac{\Pi_{F F F}^{1}}{r}-\beta \bar{C}^{* *}\right] \\
+\left[\frac{\rho_{2}\left(G_{2,3}\right)\left[1-\rho_{3}\left(G_{2,3}\right)\right]}{1-\left[1-\rho_{2}\left(G_{2,3}\right)\right]\left[1-\rho_{3}\left(G_{2,3}\right)\right]}\right]\left[\frac{\Pi_{F F D}^{1}}{r}-\beta \bar{C}^{* *}\right] \\
+\left[\frac{\left[1-\rho_{2}\left(G_{2,3}\right)\right] \rho_{3}\left(G_{2,3}\right)}{1-\left[1-\rho_{2}\left(G_{2,3}\right)\right]\left[1-\rho_{3}\left(G_{2,3}\right)\right]}\right]\left[(1-\beta) \frac{\Pi_{F D F}^{1}}{r}+\beta \frac{\Pi_{D F F}^{1}}{r}\right]-(1-\beta) C^{*}
\end{gathered}
$$

The subgame $G_{1,3}$. Again we previously obtained

$$
\begin{gathered}
\rho_{1}\left(G_{1,3}\right)=\frac{\frac{\Pi_{D F F}^{3}}{r}-\left(\frac{\Pi_{F D F}^{3}}{r}-C^{* *}\right)}{\frac{\Pi_{F F F}^{3}}{r}-\frac{\Pi_{F D F}^{3}}{r}} \\
\rho_{3}\left(G_{1,3}\right)=\frac{(1-\beta)\left(\frac{\Pi_{D F F}^{1}}{r}-\frac{\Pi_{F F D}^{1}}{r}+\bar{C}^{* *}\right)}{\frac{\Pi_{F F F}^{1}}{r}-\frac{\Pi_{F F D}^{1}}{r}}
\end{gathered}
$$

so

$$
\begin{aligned}
V^{1}(D F D \mid & \left.G_{1,2,3}\right)=V^{1}\left(D F D \mid G_{1,3}\right)-(1-\beta) C^{*} \\
= & {\left[\frac{\rho_{1}\left(G_{1,3}\right) \rho_{3}\left(G_{1,3}\right)}{1-\left[1-\rho_{1}\left(G_{1,3}\right)\right]\left[1-\rho_{3}\left(G_{1,3}\right)\right]}\right]\left[\frac{\Pi_{F F F}^{1}}{r}-(1-\beta) \bar{C}^{* *}\right] } \\
& +\left[\frac{\rho_{1}\left(G_{1,3}\right)\left[1-\rho_{3}\left(G_{1,3}\right)\right]}{1-\left[1-\rho_{1}\left(G_{1,3}\right)\right]\left[1-\rho_{3}\left(G_{1,3}\right)\right]}\right]\left[\frac{\Pi_{F F D}^{1}}{r}-(1-\beta) \bar{C}^{* *}\right] \\
& +\left[\frac{\left[1-\rho_{1}\left(G_{1,3}\right)\right] \rho_{3}\left(G_{1,3}\right)}{1-\left[1-\rho_{1}\left(G_{1,3}\right)\right]\left[1-\rho_{3}\left(G_{1,3}\right)\right]}\right]\left[(1-\beta) \frac{\Pi_{D F F}^{1}}{r}+\beta \frac{\Pi_{F D F}^{1}}{r}\right]
\end{aligned}
$$


The subgame $G_{12}$ As before we have

$$
\rho_{1}\left(G_{1,2}\right)=\rho_{2}\left(G_{1,2}\right) \equiv \rho_{12}\left(G_{1,2}\right)=\frac{(1-2 \beta)\left(\frac{\Pi_{D F F}^{1}}{r}-\frac{\Pi_{F D F}^{1}}{r}+C^{* *}\right)}{\frac{\Pi_{F F F}^{1}}{r}-(1-\beta) \frac{\Pi_{F D F}^{1}}{r}-\beta \frac{\Pi_{D F F}^{1}}{r}-\beta C^{* *}}
$$

so

$$
\begin{gathered}
V^{1}\left(D D F \mid G_{1,2,3}\right)=V^{1}\left(D D F \mid G_{1,2}\right)=\left(\frac{\rho_{12}\left(G_{1,2}\right)}{2-\rho_{12}\left(G_{1,2}\right)}\right) V^{1}\left(F F F \mid G_{1,2}\right) \\
+\left(\frac{1-\rho_{12}\left(G_{1,2}\right)}{2-\rho_{12}\left(G_{1,2}\right)}\right) V^{1}\left(F D F \mid G_{1,2}\right)+\left(\frac{1-\rho_{12}\left(G_{1,2}\right)}{2-\rho_{12}\left(G_{1,2}\right)}\right) V^{1}\left(D F F \mid G_{1,2}\right) \\
=\left(\frac{\rho_{12}\left(G_{1,2}\right)}{2-\rho_{12}\left(G_{1,2}\right)}\right)\left(\frac{\Pi_{F F F}^{1}}{r}-C^{* *}\right)+\left(\frac{1-\rho_{12}\left(G_{1,2}\right)}{2-\rho_{12}\left(G_{1,2}\right)}\right)\left[(1-\beta)\left(\frac{\Pi_{F D F}^{1}}{r}-C^{* *}\right)+\beta \frac{\Pi_{D F F}^{1}}{r}\right] \\
+\left(\frac{1-\rho_{12}\left(G_{1,2}\right)}{2-\rho_{12}\left(G_{1,2}\right)}\right)\left[(1-\beta) \frac{\Pi_{D F F}^{1}}{r}+\beta\left(\frac{\Pi_{F D F}^{1}}{r}-C^{* *}\right)\right]
\end{gathered}
$$

this supplies all the terms necessary to compute and simulate $\rho_{3}\left(G_{1,2,3}\right)$. 


\section{References}

Aoki, M., "Aspects of the Japanese Firm," in The Economic Analysis of the Japanese Firm, edited by M. Aoki (Amsterdam: North-Holland, 1984).

Belderbos, R., "Anitdumping and Tariff Jumping: Japanese Firms' DFI in the European Union and United States." Weltwirtschaftliches Archiv, 133 (1997), 419-457.

Belderbos, R. and L. Sleuwaegen, "Japanese Firms and the Decision to Invest abroad: Business Groups and Regional Core Networks, "Review of Economics and Statistics, 77 (214220).

Bruce A. Blonigen and Robert C. Feenstra, "Protectionist Threats and Foreign Direct Investment" NBER working paper 5475, 1996.

Dewenter, Kathryn L.; Warther, Vincent A, "Dividends, Asymmetric Information, and Agency Conflicts: Evidence from a Comparison of the Dividend Policies of Japanese and U.S. Firms," Journal of Finance; v53 n3 June 1998, pp. 879-904.

Christopher J. Ellis and Dietrich Fausten, "Strategic FDI and Industrial Ownership Structure" Working paper \#229, University of Oregon, 2000.

Robert C. Feenstra and Gordon H. Hanson, "Foreign Direct Investment and Relative Wages: Evidence from Mexico's Maquiladoras," Journal of International Economics, v42 n3-4 May 1997, pp. 371-93.

Flath, "Shareholding in the keiretsu, Japan's Financial Groups," Review of Economics and Statistics, 74 (1993), 249-257.

Flath, David, "The keiretsu Puzzle," Journal of the Japanese and International Economies; v10 n2 June 1996, pp. 101-21.

Drew Fudenberg and Jean Tirole, "Preemption and Rent Equalization in the Adoption of New Technology," Review of Economic Studies, LII, 1985, pp. 383-401

Fukao, K., T. Izawa, M. Kunimori and T. Nakakita," "R7D Investment and Overseas Production: An Empirical Analysis of Japan's Electric Machinery Industry based on Corporate Data," BOJ Monetary and Economic Studies, 12 (Dec 1994), 1-60.

Hennart J-F. and Y. -R. Park, "Location, Governance, and strategic Determinants of Japanese Manufacturing Investments in the United States," Strategic Management Journal, 15 (1994), 419-436.

James R. Hines Jr., "Tax Sparing" and Direct Investment in Developing Countries," NBER working paper 5475, September 1998.

Hirschmeyer, J. and T. Yui, The Development of Japanese Business (Cambridge, MA: Harvard University Press, 1975).

Hoshi, T., A. Kashyap, and D. Scharfstein, "Corporate Structure, Liquidity, and Investment: Evidence from Japanese Industrial Groups," Quarterly Journal of Economics, (Feb 1991), $33-60$.

Kimura, Yui; Pugel, Thomas A., "keiretsu and Japanese Direct Investment in US Manufacturing," Japan and the World Economy; v7 n4 November 1995, pp. 481-503. . 
Kogut, Bruce and Sea Jin Chang, "Technological Capabilities and Japanese Foreign Direct Investment," Review of Economics and Statistics, 73 (August 1991), 401-13.

Kogut, Bruce and Sea Jin Chang, "Platform Investments and Volatile Exchange Rates: Direct Investment in the USA by Japanese Electronics Companies," Review of Economics and Statistics, 78 (August 1996), 221-31..

Ping Lin and Kamal Saggi, "Incentives for Foreign Direct Investment under Imitation" Canadian Journal of Economics, November, 1999 Vol. 32 No.5.

McCormack, J., "The Japanese Way: The Relationship between Financial Institutions and Nonfinancial Firms," Policy Staff Paper, No 94/16 (Ottawa: Canadian Department of Foreign Affairs and International Trade, 1994).

McKenzie, C. R., "Japanese Direct Foreign Investment: The Role of Technology and keiretsu," Working Paper Series, Macquarie University (January 1997).

Orru, M., G. G. Hamilton and M. Suzuki, "Patterns of Inter-Firm Control in Japanese Business," Organization Studies, 10 (1989), 549-74.

Ouchi, W., "Markets, bureaucracies, and clans," Administrative Science Quarterly, 25 (1980), 129-41.

Rauch, James and Robert C. Feenstra, "Introduction to Symposium on "Business and Social Networks in International Trade," Journal of International Economics, 48 (June 1999), 3-6.

Suzuki, Kazuyuki, "R\&D Spillovers and Technology Transfer among and within Vertical keiretsu Groups: Evidence from the Japanese Electrical Machinery Industry," International Journal of Industrial Organization; v11 n4 1993, pp. 573-91.

Yu, C. -M., "The Experience Effect and Foreign Direct Investment," Weltwirtschaftliches Archiv, 126 (1990), 561-580.. 